\title{
Introducción a la antropología general de Pierre Bourdieu
}

Intentar resumir treinta y cinco intensos, imaginativos y fértiles años de trabajo, más de veinte libros y más de doscientos cincuenta artículos ${ }^{1}$ en unas pocas páginas, no es una tarea prácticamente irrealizable exclusivamente por el volumen ingente de la producción científica del autor que nos ocupa. Lo es, también, por la casi inabarcable variedad de los temas investigados y la heterogeneidad aparente de unas materias cuyo nexo no se deja entrever fácilmente tras una lectura superficial, o tras una lectura que sólo se sienta cómoda en los estrechos e interesados límites de las respectivas tradiciones disciplinares; por el vigor y la vehemencia de una prosa que no se pliega a las simplificaciones del lenguaje cotidiano al querer romper conscientemente con las evidencias espontáneas que éste nos proporciona; por el desarrollo y articulación de un conjunto de conceptos que, aunque tomados en buena medida de la tradición sociológica precedente, permanecen abiertos y en constante evolución.

El hecho, sin embargo, de que el conjunto de la obra de Pierre Bourdieu sea casi completamente desconocido en el panorama de la academia española, excepción hecha de algunas aproximaciones excesivamente laxas o francamente simplificadoras ${ }^{2}$, y convencidos de la

Para una bibliografía completa actualizada hasta el año 1992, tanto para artículos y libros originales como para sus respectivas traducciones, consultad Yvette Drtsal'T, Bibliographie des travaux de Pierre Bourdieu (Paris: Centre de Sociologie Europeenne du Collège de France et de l'Ecole des Hautes Ėtudes en Sciences Sociales, 1989, 52 p.). Pueden manejarse también las recopilaciones de Richard Harker, Cheleen Mahar y Chris Wilkes, An introduction to the work of Pierre Bourdieu (Hampshire and London: The MacMillan Press Ltd, 1990, 247 p., pp. 226-232); la de Loï J. D. WACQUiANI, An invitation to reflexive sociology (Chicago: The University of Chicago Press, 1992, 332 p., pp. 273-282); y la versión francesa de la obra anterior, Pierre Bol:Rdiev avec Loï J. D. WACQUiANT, Réponses. Pour une antbropologie réflexive (Paris: Éditions du Seuil, 1992, 270 p., pp. 245-253). Estos tres últimos trabajos, sin embargo, dado que se dirigen a un público angloparlante, recogen casi exclusivamente aquellos títulos que han sido traducidos al inglés.

2 Sin duda, la aproximación más afinada en la bibliografia española al trabajo de Bourdieu, si bien se refiere exclusivamente a aquella parte de su actividad dedicada al estudio del funcionamiento discriminatorio del sistema de enseñanza, es la sIntroducción. que J. L. ABELLÁn escribió para la edición española de La Reproduction. Eléments pour une théorie du système d'enseignement (Paris: Ed. de Minuit, 1970; ed.esp. La Reproducción: Barcelona, Laia, 1979). No en vano, se le atribuye a J. L. Aranguren la presentación e introducción en España 
transcendencia que sus trabajos han tenido, están teniendo y tendrán en la progresión de todas las áreas de la ciencia social ${ }^{3}$, nos lleva a plantear

de esta obra. Puede consultarse también, más por su carácter pionero que por la profundidad y acierto del texto, el trabajo de J. J. SÁNCHFZ DE: HORCAIO, La cultura, reproducción o cambio: el análisis sociológico de Pierre Bourdieu (Madrid: Centro de Investigaciones Sociológicas, Colección Monografias núm. 23, 1979, 304 p.). Recomendable, por su concisión e incisividad, es el comentario de J. Ibániz, "En los dominios del gusto» (El País, domingo 23 de octubre de 1988, p. 21), a las ediciones españolas de La distinción. Criterio y bases sociales del gusto (Madrid: Taurus, 1988, 597 p.) y Cosas dichas (Barcelona: Gedisa, 1988, 200 p.). También, su introducción previa al pensamiento de Bourdieu en "El más sólido científico social (El País, martes 26 de abril de 1988, p. 35), que comenzaba afirmando: "Bourdieu es, probablemente, el científico social más sólido de nuestro tiempon. Más reciente, aunque de menos calado, es la aproximación sucintamente biográfica de José E. RonRigulz-IBánfz "Un antiguo chico de provincias llamado Pierre Bourdieun (Madrid: Revista de Occidente, núm. 137, octubre 1992, pp. 183-187). Por último, más a beneficio de inventario que por la calidad de la reflexión, puede citarse el texto de Isidoro Morfno, "Identidad y rituales" (Joan Prat, Ubaldo Martinfz, Jesús Contrekas e Isidoro Morrno, Antropología de los pueblos de España, Madrid, Taurus, 1991, 793 p.), pp. 601-636, donde se trata de equiparar sin fundamento el concepto bourdieuano de babitus con el de matriz cultural (p. 603). En esta misma obra, pueden encontrarse alusiones sucintas al trabajo de Boırimen en los artículos de: Abraham Iszafvich, "Emigrantes, solteronas y curas: la dinámica de la demografía en las sociedades campesinas españolas", (op.cit), pp. 280-293 (sobre estrategias matrimoniales y soltería); Jesús Conrrrkas, "Los grupos domésticos: estrategias de producción y de reproducción", (op. cit), pp. 343-380 (sobre estrategias matrimoniales); Susana NAROTZKY, "La renta del afecto: ideología y reproducción social en el cuidado de los viejos", (op. cit), pp. 464-474 (sobre el travestimiento simbólico de las estrategias de dominación); Cristina BORIERias, "Proyectos, estrategias familiares y trayectorias sociales femeninas", (op. cit), pp. 475-484 (sobre la distinta trayectoria social de hombres y mujeres); Raul ITURRA RFIDONio, "Factores de producción social en sistemas rurales: trabajo, producción de productores y pecado en aldeas campesinas", (op. cit), pp. 485-498 (referencia al celibato como condición necesaria para el mantenimiento e indivisión del patrimonio familiar; breve referencia a la reproducción de las condiciones necesarias para la reproducción de los grupos sociales); Lourdes MF́ndez, "Reflexión sobre la poco común producción de las pequeñas mujeres", (op. cit.), pp. 700-709 (mención de las operaciones necesarias para el control científico de los hechos sociales).

" Como así lo demuestran los más de ciento veintiseís artículos y libros que hemos contabilizado en la bibliografía internacional a propósito de los trabajos de Pierre Bourdieu. Entre los más importantes, dependiendo de los temas tratados y analizados, podriamos entresacar los de Alain Accardo, Initiation à la sociologie de l'illusionnisme social. Lire Bourdieu (Bordeaux: Editions Le Mascaret, 1983); Alain AcCARDO y Philippe Corcuff (eds), La sociologie de Pierre Bourdieu. Textes chosis et commentés (Bordeaux: Editions Le Mascaret, 1986); Michel ARl.IAlIx, .Review of 'Homo Academicus'., Retue Française de Sociologie, 26, núm. 4, (1985), pp. 713-719; Bennet BrRgir, "Taste and domination", American Joumal of Sociology, 91, núm. 6, (1986), pp. 1445-145; Cornelia BонN, Habitus und kontext. ein kritischer beitrag zur socialtheorie Bourdieus (Darmstadt: Westdeutscher Verlag, 1991); François Bon e Yves Schfmeil, -Le rationalisation de l'inconduite: comprende le statut du politique chez Pierre Bourdieu-. Revue Française de Sociologie, 30, núm. 6, (1980), pp. 1198-1230; Rogers Bri'BaKER, -Rethinking classical sociology: the sociological vision of Pierre Bourdieu., Theory and Society, 14, núm. 6. (1985), pp. 745-775; Craig Calmoun, Edward Lipima y Moishe Postone (eds), Exploring the social theories of Pierre Bourdieu (Cambridge: The Polity Press, 1992); Michel de Cerreal, "Foucalt and Bourdieu*, pp. 45-60, en The practice of everyday life (Berkeley and Los Angeles: 
la conveniencia de desarrollar una lectura de su obra que, si bien será personal y globalizadora, tenga al menos la virtud de establecer una ilación lógica entre todos los campos de su indagación y entre las herramientas conceptuales utilizadas para su exploración.

No hacemos sino sumarnos, con esto, al reconocimiento internacionalmente unánime del rigor, consistencia y profundidad de la obra del que nosotros consideramos el científico social más destacado de nuestro tiempo.

\section{CRÍtICA DEL INTELECTUALOCENTRISMO O DE LA RAZÓN TEÓRICA}

Situaremos el punto de partida de esta revisión en el problema que, sin lugar a dudas, constituye el centro de las polémicas de la ciencia social desde el momento mismo de su constitución: nos referimos a la dicotomía entre las aproximaciones objetivistas y subjetivistas * a la rea-

University of California Press, 1984,229 p.); G. CRisw, "The use of the concept of strategy in recent sociological literature», Sociology. 23, núm. 1 (1989), pp. 1-24; Paul Dimanirin, "Review essay on Pierre Bourdieu*, American Joumal of Sociologv, 84, núm. 6, (1979), pp. 1460-1474; Mary Dovalas, "Good taste: review of Pierre Bourdieu, 'La distinction'", Times Literary Supplement, February 13, (1981), pp. 163-169; Anthony Gunpss, "The politics of taste", Partisan Review, 53, núm. 2, (1986), pp. 300-305; Richard K. Hakklk, "On reproduction, habitus and education", British Jourmal of Sociology of Education, 5, núm. 2, (1984), pp. 117-127, Richard JFnkins, "Pierre Bourdieu and the reproduction of determinism", Sociology, 16. num. 2, (1982), pp. 270-281, "Language, symbolic power and communication: Bourdieu's 'Homo Academicus", Sociology, 23, núm. 4, (1989), pp. 639-645; Christian Joppk1, The cultural dimension of class formation and class struggle: on the social theory of Pierre Bourdieu*, Berkeley Joumal of Sociology, 31, (1986), pp. 53-78; G. Lakомsk, "On agency and structure: Pierre Bourdieu and J. C. Passeron's theory of symbolic violence», Curriculum Inquiry, 14, núm. 2. (1984), pp. 151-163; Don Min.tr y Jan Branion, "Pierre Bourdieu: culture and praxis", pp. 210-225, en Creating culture: profiles in the study of culture, editado por Diane J. Aisiv-Broos (Sidney: Allen and Unwin, 1987); Dag Östekrekg, "Bourdieu's doctrine of habitus and the socio-cultural fields;, pp. 173-180, en Metasociology: an inquiry into the origins and validity of social thought (Oslo: Norwegian University Press, 1988); James M. O $\uparrow k, \ldots$, "Culture as a fundamental dimension of experience: a discussion of Pierre Bourdieu's theory of the human habitus", Human Studies, 4, núm. 3, (1981), pp. 279-297; Jean-Claude PAsskon, "La signification des théories de la reproduction socio-culturellex, International Social Science Journal, 38, núm. 4 (1986), pp. 619-629; Derek RoвBıss, The work of Pierre Bourdieu: recognizing society (London: Milton Keynes, Open University Press, 1991); Theodore R. S(HAlzk. "Overdue analysis of Bourdieu's theory of practice., Inquiry, 30, núm. 1-2, (1987), pp. 113-136; David Su Ak1\%, "Pierre Bourdieu: the cultural transmission of social inequality", Harvard Educational Review, 47 , (1977), pp. 545-554; John B. THOMpon, symbolic violence: language and power in the sociology of Pierre Bourdieu, pp.42-72, Studies in the theory of ideology (Cambridge: Polity Press, 1984); Loï J. WarQlanr, "Towards a reflexive sociology: a workshop with Pierre Bourdieu., Sociological Theory, 7, núm. 1, (1989), pp. 26-63.

- Si hay una cita que resume claramente el estado de ánimo de la antropología a este respecto, es la que puede encontrase en Enrique LI:QuF, Del conocimiento antropológico 
lidad social y a todas y cada una de las parejas de opuestos que siguen lógicamente a la antítesis principal, estas son, estructura/acción, sociedad/ individuo, coacción/espontaneidad, necesidad/libertad, obligación/elección, macroanálisis/microanálisis, sumisión/resistencia, etc. Para no abundar innecesariamente en el contenido de una disputa que es bien conocida, quepa decir, al menos, que la perspectiva objetivista, amparada en la necesidad real de romper con la experiencia espontánea y cotidiana de la realidad social para crear una ciencia de lo social, acaba, en todas aquellas ocasiones en que no se toma la molestia previa de preguntarse por las condiciones que hacen particularmente posible a unos pocos sustituir la experiencia práctica y perentoria de las cosas sociales por una experiencia escolástica y distanciada de las mismas, haciendo pasar el modelo de la realidad por la realidad del modelo, esto es, dándole a la teoría explicativa de la realidad social que construyen una realidad que no tiene más que por la situación social de quienes la proponen y defienden. A los amantes de los preceptos metodológicos, que confiando en una fuente de opinión entregan crédulamente su pensamiento y su actividad a un conjunto de órdenes bien establecidas, les basta con seguir mecánicamente esas normas para despreocuparse y desvincularse del problema que sigue subyaciendo a toda teoría de los social, este es, el de saber cuales son las condiciones sociales que concurren en una posición determinada para hacer de la visión y lectura de los que allí se sitúan una visión más aguda y una lectura más honda que cualquiera otra que pudiera proponerse y que proviniera de otra posición alternativa. No se trata de rechazar en conjunto las reglas del método durkheimiano y renunciar al avance indiscutible que supuso desconfiar de las evidencias primeras ${ }^{5}$ para construir

(Madrid: Centro de Investigaciones Sociológicas, Siglo XXI. 1990, 250 p.): «El gran problema en el que se siguen debatiendo las ciencias sociales en nuestros días es evitar caer en las garras de la Escila de la objetividad absoluta, fisicalista y reduccionista, y la Caribdis del más puro subjetivismo, que hipervalora la configuración del objeto por el sujeto que lo percibe y lo concibe. (p. 82).

Toda la obra de Le metier de sociologue, trabajo conjunto de Pierre Bolrimfi, JeanClaude Chamborfion y Jean-Claude Passfron (Paris: Ecole Practique des Hautes Etudes y Mouton \& Co., 1973; ed. esp. El oficio de sociólogo, Madrid, Siglo XXI de España Editores, 1989. decimosegunda edición, 372 p.), se encarga de recordar hasta que punto es necesario dominar las evidencias infraconscientes sobre la realidad social circundante, presentes de forma enteramente natural en la percepción cotidiana de los asuntos sociales, para que no se apoderen de los enunciados conscientemente formulados sobre esa misma realidad. Esto vale tanto para el común de los agentes, que en sus actividades cotidianas juegan el juego de las categorizaciones cruzadas, como para aquellos otros que. profesionales del juicio, producen categorizaciones sobre esas actividades corrientes, ejercicio que, dicho sea de paso, no les asegura ninguna prelación sobre el resto de los juicios por el simple hecho de estar pretendidamente ajustados a normas más o menos regularizadas de observación. Dice Bourdieu: ...la familiaridad con el universo social constituye el obstáculo epistemo- 
una ciencia de la génesis de esas evidencias, ni de tributar un reconocimiento fetichista y encantado al rigor y eficacia de las diversas técnicas que aseguran el advenimiento de mundos de verdades inamovibles, ni tampoco de una interrogación torturada, individualista y desencantada a la manera postmoderna sobre los límites de la comunicación ${ }^{\circ}$ : se trata de saber qué es lo que le ocurre al objeto sobre el que nos interrogamos cuando no nos interrogamos anticipadamente sobre nuestra relación con el objeto, lo que es lo mismo, qué clase de objeto construimos cuando, abdicando de nuestra obligación original de rechazar la comodidad y familiaridad de las certezas de nuestro juicio, desobedecemos el mandato durkheimiano de tratar a todos los hechos sociales como cosas para reservar una posición privilegiada, a salvo de toda reducción, desde la que emitir enunciados privilegiados sobre aquellos lógico por excelencia para el sociólogo, porque produce continuamente concepciones
o sistematizaciones ficticias, al mismo tiempo que sus condiciones de credibilidad... El
sociólogo no ha saldado cuentas con la sociología espontánea y debe imponerse una polé-
mica ininterrumpida con las enceguedoras evidencias que presentan. a bajo precio,
las ilusiones del saber inmediato y su riqueza insuperable. (p. 27). Más explicitamente si cabe:
"La sociología no puede construirse como ciencia efectivamente separada del sentido común
sino bajo la condición de oponer a las pretensiones sistemáticas de la sociologia espon-
tánea la resistencia organizada de una teoría del conocimiento de lo social cuyos princi-
pios contradigan, punto por punto, los supuestos de la filosofía primera de lo social.
(p. 27).

- Buen ejemplo de nihilismo improductivo y aristocrático, que pretendiendo haber hallado los límites de la comunicación entre culturas propone volver a una forma completamente ingenua de positivismo representativo donde se permita que las toces bablen por si mismas y que los juicios se expresen libremente, es el trabajo conjunto de J. Curford y G. E. Marcus (eds.), Retóricas de la antropología (Madrid: Ediciones Júcar, 1991, 390 p.; ed. orig. Writing culture. The poetics and politics of ethnography, Berkeley, University of California Press, 1986, 305 p.). Todo el desorden epistemológico y la ingenuidad política del movimiento postmoderno en antropología, puede estar contenido en esta cita: "La idea fundamental es la de toparse con múltiples voces que hablen por sí mismas, dejando mi propia voz de autor muda, marginalizada, reducida al simple comentario... Mientras ello acontezca de veras el lector escuchará las versiones originales y directas. El texto, pues, no estará herméticamente sellado... Si son múltiples las voces amasijadas en este experimento, espero, también, que sean múltiples los lectores capaces de escucharlas, de sentirlas... Mediante la invocación de discursos propios a un número considerable de grupos distintos, compondremos una sinfonía absolutamente polifónica, colorista, llena de matices. El discurso que es inherente al texto no queda lastrado, asi, por una huera retórica profesional o por un autoritarismo academicista que desprecie las voces no profesionales.... (M. M. J. FISCHFR, «El etnicismo y las artes postmodemas de la memoria., pp. 269-320, en J. Ci.fForor, y G. E. Marr.us, op. cit., pp. 278-279). El libro de P. RaBinow, Reflections on fieldwork in Morocco (Berkeley: University of California Press, 1977,170 p.), es más mesurado a este respecto, aunque el problema de la representación, como queremos hacer resaltar, no radica en la introspección personalizada y anhelante de un sólo científico, sino en el control disciplinar de las alteraciones a las que se somete al objeto por el hecho de proyectar sobre él categorías que pertenecen a las convicciones y certezas espontáneas. propias de la condición de los científicos. 
hechos ${ }^{7}$. En demasiadas ocasiones, bajo el disfraz de la sociología científica, no se nos ofrece sino el relato de la relación irreflexiva del científico con el objeto, es decir, la verdad fenomenológica e instantánea de su experiencia personal del objeto, cuestión que nos pone ya sobre aviso del profundo parentesco que existe entre posiciones supuestamente antagónicas como pretenden ser el objetivismo y el subjetivismo. Debe entenderse ahora con más facilidad por qué, por ejemplo, todos los modelos sobre el funcionamiento de la realidad social que proponen las teorías objetivistas, tienen ese aspecto rígido y mecánico que, a fuerza de querer explicarlo todo, explican cada vez menos: al procurarse un patrón explicativo que sustituye, como dice Bourdieu, la relación práctica con la práctica por la relación teórica con la práctica, no puede descifrarse la práctica de los agentes observados sino de una manera "negativa", esto es, sujeta a las reglas y leyes propias del modelo objetivado de las prácticas que es resultado de la relación infraconsciente que el observador mantiene con el objeto ${ }^{8}$. Por eso, la sujeción incontestable de los "sujetos" (donde el mismo lenguaje se encarga de recalcar el sometimiento) a las estructuras de todo tipo que los antropólogos se encargan de hacer existir sin darnos nunca pistas de la razón de su existencia y su pervivencia, no es tanto una realidad irrebatible como el resultado de la alteración ontológica a la que el observador somete al objeto. En la edición inglesa de Esquisse d'une théorie de la practique, précédé de trois études d'ethnologie kabyle, titulada Outline of a theory of practice y que contiene algunas modificaciones sobre el texto original, puede leerse ${ }^{\text {: }}$

\footnotetext{
Algunos eminentes postestructuralistas franceses, como Roland BARTHFs, La aventura sémiológica (Barcelona: Fditorial Paidós. 1990. 352 p.; ed. orig. L'aventure sémiologique. Paris, Fditions du Seuil, 1985), cuyo texto original es de 1974. se acercaban ya a la formulación que después perfeccionaría Bourdieu, aunque los resabios psicoanalíticos no le permitieran profundizar en la dimensión suciológica del problema del conocimiento: ‘Afirmándose en las adqusiciones del psicoanálisis se interroga por el lugar desde donde habla, interrogación sin la cual toda ciencia y toda crítica ideológica son ridículas. Para la semilogía (por lo menos así deseo que sea) no existe una extraterritorialidad del sujeto, aunque se trate de un sabio. respecto de su discurso. Dicho de otra manera, la ciencia, en última instancia, no conoce ningún lugar de seguridad, y en esto debería reconocerse como escrituran (p. 13).

Fn Le sens pratiçue (Paris: Editions de Minuit, 1980, 475 p.; ed. esp. El sentido práctico, Madrid, Taurus Fdiciones, 1991, 451 p.) y en articulos previos como se sens pratique", Actes de la Recherche en Sciences Sociales (1. février. 1976), pp. 43-86, podemos leer: -El intelectualismo está inscrito en el hecho de introducir en el objeto la relación intelecutal con el objeto, de sustituir la relación práctica con la práctica por la relación que el observador mantiene con su objeto. Los etnólogos no podrán escapar de todas sus interrogaciones metafisicas sobre el estatus ontológico o, incluso, el elugar" de la cultura, si no es a condición de objetivar su propia relación con el objeto, la del extranjero que debe procurarse el sustituto del dominio príctico bajo la forma de un modelo objetivado..." (p. 62).

Pierre Botrint, Esquisse d'une théorie de la pratique. précédé de trois études d'ethnologie kabule (Genève: Droz, 1972, 269 p.): Outline of a theory of practice (Cambridge: Cambridge University Press, 1977,248 p.).
} 
El privilegio práctico con que toda actividad científica se alza nunca gobierna más sutilmente esa actividad (dado que la ciencia no sólo presupone una ruptura epistemológica sino también una separación social) que cuando, no reconocido como privilegio. conduce a una teoría implícita de la práctica que es el corolario de la negación de las condiciones sociales en que la ciencia es posible. La relación particular del antropólogo con el objeto de su estudio contiene las elaboraciones de una distorsión teórica puesto que su situación como observador, excluido del juego real de las actividades sociales por el hecho de que no tiene lugar (excepto por elección o por medio del juego) en el sistema observado y no tiene necesidad de hacerse un lugar allí, le inclina a una representación hermeneútica de las prácticas, llevándole a reducir todas las relaciones sociales a relaciones comunicativas $y$. más precisamente, a operaciones de descodificación ".

Toda esta disquisición sería desestimable si los efectos que la "teoría" tuviera sobre la "realidad" fueran inocuos, es decir, si "teoría" y "realidad" fueran dos términos sin más relación que la que una fotografía puede mantener con lo retratado. Sin embargo, la teoría del conocimiento y la teoría política son inseparables, o, más bien, toda teoría del conocimiento tiene, en su aplicación, unos efectos políticos inmediatos ": no se trata, como se está abocado a creer ingenuamente y como toda la pedagogía de las técnicas se encarga de hacernos creer, de decir la verdad sobre el mundo social, sino de decir la verdad sobre las disputas por establecer la verdad sobre el mundo social ${ }^{12}$. Cuando la ciencia sociológica inter-

\section{Pierre Borrint, 1977, op. cit, p. 1.}

1 En "Le paradoxe du sociologue", pp. 86-94, Questions de sockologe (Paris: Les Editions de Minuit, 1984, 277 p.), dice Pierre Bor k1m1: :La idea central que me gustaria avanzar hoy es que la teoría del conocimiento y la teoría política son inseparables: toda teoria política encierra, en el estado implícito al menos, una teoría de la percepción del mundo social y las teorías de la percepción del mundo social se organizan según oposiciones muy análogas a aquellas que encontramos en la teoría de la percepción del mundo natural. (p. 86). También, más explícitamente si cabe, dice en el Outline of a theory of practice' (op.cit) "La teoria del conocimiento es una dimensión de la teoría política porque el poder simbólico específico de imponer los principios de construcción de la realidad -en particular, de la realidad sociales una dimensión fundamental del poder políticon (p. 165).

12 En Leçon sur la Leçon (Paris: Les Éditions de Minuit, 1982, 56 p.), lección inaugural pronunciada por Bor'rdir en el Colegio de Francia el viemes 23 de abril de 1982, establecía clara y sucintamente el objeto de la sociología: "Para romper con la ambición. que es la de las mitologías, de fundar en la razón las divisiones arbitrarias del orden social, y en primer lugar la división del trabajo, y de dar así una solución lógica o cosmológica al problema de la clasificación de los hombres, la sociología debe tomar por objeto, en lugar de dejarse tomar, la lucha por el monopolio de la representación legítima del mundo social, esta lucha de clasificaciones que es una dimensión de toda clase de lucha de clases, clases de edad, clases sexuales o clases sociales" (p. 14); "Así, es la misma cosa descubrirse inevitablemente comprometido en la lucha por la construcción y la imposición de la taxonomía legítima, y de darse por objeto, pasando al segundo grado, la ciencia de esta lucha, es decir el conocimiento del funcionamiento y de las funciones de las instituciones que se encuentran comprometidas - como el sistema escolar o los grandes organismos oficiales de empadronamiento y de estadística social- Pensar como tal el espacio de la lucha de las clasificaciones - y la posición 
viene antirreflexivamente en estas disputas ofreciendo el fruto inmaduro de una relación inconsciente con el objeto como si fuera un juicio irrefutable, puede acabar, muy bien, haciendo realidad lo que dice que es real, porque como sabe la teoría social desde hace tiempo, y más aún si los enunciados provienen de una fuente a la que públicamente se le reconoce una prelación especial, es perfectamente factible arriesgar profecias autorrealizadoras que, como vaticinios no necesariamente verdaderos, generan las condiciones de su propia verificación (lo que puede instar a los agentes a que contribuyan activamente a la generación de esas condiciones de verificación) ${ }^{13}$. Cuando, como decíamos, la sociología olvida que el mundo social es, antes que nada, el espacio donde se dirime contínuamente la verdad sobre ese mundo, se comporta de una forma extremadamente ingénua porque, como todo el positivismo, toma los problemas que el lenguaje común establece como problemas dignos de preocupar y ser estudiados (la inmigración, la drogadicción o cualquier otro), como problemas con existencia real independiente de quien los plantea como problemas en vez de preguntarse por el proceso y la génesis del establecimiento de una cuestión determinada como problema. Temerosos de llegar después de la batalla al planteamiento, comentario y resolución de los problemas que los periodistas y profesionales mediáticos se encargan de tomar del lenguaje común, medrosos de no tener la respuesta agil y precisa en el momento que el micrófono de la actualidad plantea la pregunta que proviene del lenguaje cotidiano, turbados de no adherirse a tiempo, mediante firma compulsiva de manifies-

del sociólogo en ese espacio o por relación a él- no conduce en modo alguno a aniquilar la ciencia en el relativismo. Sin duda el sociólogo no es más el árbitro imparcial o el espectador divino, solo apto para decir donde está la verdad -0 , para hablar como el sentido común, que tiene razón-, ese que viene a identificar la objetividad con una distribución ostentatoriamente equitativa de sinrazones y razones. Pero es él el que se esfuerza por decir la verdad de las luchas que tienen por apuesta -entre otras cosas- la verdad. Por ejemplo, en lugar de resolver entre aquellos que afirman y aquellos que niegan la existencia de una clase, de una región o de una nación, trabaja para establecer la lógica específica de esta lucha y para determinar, a través de un análisis del estado de la relación de fuerzas y de los mecanismos de su transformación, las oportunidades de los diferentes campos" (pp. 15-16). Este texto, como tantos otros en el trabajo de Bourdieu, recibe una influencia directa de Nietzsche ( $L a$ genealogia de la moral, Madrid: Alianza Editorial, 1992, 203 p.) y de sus alegatos contra los científicos contemporáneos que se hallan muy lejos de ser espíritus 'libres': 'pues creen todavía en la verdad' (p. 173)... En este punto es necesario detenerse y reflexionar largamente. La ciencia misma necesita en adelante una justificación... la misma voluntad de verdad necesita una justificación, hay aquí una laguna en toda filosofía - ¿a qué se debe?... a que la verdad misma fue puesta como ser, como Dios, como instancia suprema, a que a la verdad no le fue licito en absoluto ser problema (pp. 174-175)... La voluntad de verdad necesita una crítica... el valor de la verdad debe ser puesto en entredicho alguna vez, por vía experimental. (p. 175).

'Esto es, por supuesto, lo que puede encontrarse en las páginas 420-421 de E. NAGel, La estructura de la ciencia. Problemas de la lógica de la investigación científica (Barcelona: Paidós, 1981, 556 p.). 
tos, a la cuestión del día, muchos sociólogos prefieren obtener el máximo de beneficios simbólicos al mínimo de esfuerzo intelectual, aunque sea al precio de jugar el juego de la actualidad, aquél que consiste en fomentar el valor de lo que se trata haciendo conocer y reconocer mediante los comentarios del experto, el valor de lo que se trata (estrategia de la que viven, dicho sea de paso, todas aquellas profesiones que, promoviendo la creencia en el valor de lo que tratan mediante inversiones personales en el asunto, acaban obteniendo los beneficios multiplicados del reconocimiento público del valor del asunto) ${ }^{14}$.

El efecto más insidioso y perverso, quizá más aún por desconocido que por activo, que se sigue del funcionamiento cotidiano del juicio científico, sobre todo cuando decide participar animadamente en el juego mediático, es el que constituye la función invariante de todos los racismos ${ }^{15}$ : cuando un grupo tiene la necesidad de justificarse de existir como existe, intenta imponer la percepción del mundo social más adecuada a sus propias condiciones, esto es, intenta hacer de la relación que guarda con el objeto considerado, la única de las relaciones legítimas y posibles, intenta producir una teodicea de sus propios privilegios. La condición intelectual, entendida como un conjunto de habitos perceptivos y cognitivos propios de un conjunto de personas que se generan en unas condiciones de producción particulares, no escapa desde luego a la especificación anterior y se comporta con toda la violencia imaginable cuando, presos de sus propias evidencias espontáneas, proyectan sobre el objeto de su análisis lo que no son sino los principios de la relación que ya mantenían previamente con ese objeto. No es casualidad, por eso, que Bourdieu tome a Kant ${ }^{16}$ como el

1. Pierre Bol:Rimfl, "Entrevista a Pierre Bourdieu, ensayista: 'Los malos sociólogos franceses tienen en España su segundo mercado:, La Vanguardia (1 de marzo de 1991), p. 38.

Consultad Pierre Bor'riff', "Le racisme de l'intelligence", Questions de sociologie (Paris: Les Editions de Minuit, 1984), pp. 264-268. También, en el mismo libro recopilatorio, Pour une sociologie des sociologues", op. cit., pp. 79-85. En Cusas dichas (Barcelona: Editorial Gedisa, 1988, 200 p.), pueden encontrarse: "El interés del sociólogo", op. cit., pp. 108-114. "Sociólogos de la creencia y creencia de los sociólogos", op. cit. pp. 93-97, y eEl campo intelectual: un mundo aparte, op. cit., pp. 143-151.

10 En La distinction. Critique sociale du jugement (Paris: Editions de Minuit, 1979, 670 p.; ed. esp. La distinción. Criterio y bases sociales del gusto, Madrid, Taurus, 1988, 597 p.), Pierre Bourdieu consagra el último de sus capítulos, titulado significativamente -Elementos para una crítica 'vulgar' de las críticas 'puras'. (pp.496-512), a poner en evidencia cómo todos los supuestos privilegios perceptivos y cognitivos asociados a la condición del intelectual, fielmente reflejados en la Crítica del juicio, no eran ni son sino la substancialización y reificación de unas condiciones de producción del conocimiento que hacen particularmente posible a unos pocos percibir y conocer de una manera determinada. Puede consultarse también, a este respecto, toda la bibliografia que Boirsirt ha producido en torno a la figura de otro filósofo universal que, con su filosofía recogida e intimista, reclamaba la universalidad de su juicio: "Lontologie politique de Martin Heidegger., Actes de la Recherche en Sciences 
ejemplo prototípico del intelectualocentrismo y de los efectos devastadores que su aristocratismo trajo a la teoría del conocimiento: la mayor parte de la humanidad queda relegada a la condición de bruta cuando se la compara con las excelencias del juicio puro, aunque nunca nos sea dado conocer cúales son las condiciones que se necesitan para producir esa forma de conocimiento, aunque se nos sustraiga permanentemente la idea misma de que los juicios no están dados de una vez para siempre desde el comienzo sino que tienen una genealogía particular que depende de unas condiciones históricamente singulares, aunque el juicio puro coincida, sospechosamente, con el juicio de quien escribe ${ }^{17}$

Sociales, 5-6, novembre (1975), pp. 109-156; L'ontologie politique de Martin Heidegger (Paris: Les Editions de Minuit, 1988); "Heidegger par Pierre Bourdieu: le krach de la philosophie", Libération, 10 mars (1988), Supplément Livres, pp. VI-VII; La ontología política de Martin Heidegger (Barcelona: Editorial Paidós, 1991, 109 p.). También, aquellos títulos que tratan de la necesidad de un replantamiento de la filosofía como tal, de la necesidad de radicar sociológicamente sus juicios para evitar las interminables y bizantinas disputas que no son mas que el ejercicio retórico y ritual de una disciplina que trata de reproducirse como tal: "The Philosophical Establishment, en Philosophy in France Today, A. Montrfiorf (ed.) (Cambridge: Cambridge University Press, 1983), pp. 1-8; "Les sciences sociales et la philosophie", Actes de la Recherche en Sciences Sociales, 47-48, juin (1983), pp. 45-52.

1- El aliento nietzscheano de la antropología de Bourdieu, se ve quizá, mejor que nunca, en este antikantismo sociológico. Decía Nirt’sche en La genealogía de la moral (Madrid: Alianza Fditorial, 1992, 203 p.): “Es indiscutible que, desde que hay filósofos en la tierra, y en todos los lugares en que los ha habido... existen una auténtica irritación y un auténtico rencor de aquéllos contra la sensualidad... igualmente existen una auténtica parcialidad y una auténtica predilección de los filósofos por el ideal ascético en su totalidad. Ambas cosas forman parte del tipo, como hemos dicho; y si ambas faltan en un filósofo, entonces éste no pasa de ser... un filósofo "por así decirlo' (p.124); ¿qué obtiene entonces el filósofo de esta alianza con los valores del ascetismo": "... al contemplarlos, el filósofo sonrie a un 'optimum' de condiciones de la más alta y osada espiritualidad -con ello no niega 'la existencia', antes bien, en ello afirma 'su' existencia y 'sólo' su existencia. y esto acaso hasta el punto de no andarle lejos este deseo criminal: perezca el mundo, hágase la filosofía, hágase el filósofo, hágame yo... ¡Ya se ve que estos filósofos no son testigos y jueces incorruptos del valor del ideal ascético! Piensan en sí mismos... Piensan en lo que precisamente a 'ellos' les resulta lo más indispensable: estar libres de coerción, perturbación, ruido de negocios, deberes, preocupaciones... al pensar en el ideal ascético los filósofos piensan en el jovial ascetismo de un animal divinizado al que le han brotado alas, y que, más que descansar sobre la vida, vuela sobre ellan (pp. 125-126). No quisiéramos olvidar aquella magnífica reflexión que Ortega y Gasset hizo al respecto en "Verdad y perspectiva", El Espectador (Madrid: Salvat Editores, 1969 [1916-1934]), 188 p.), pp. 17-23: "Cuando leo que Aristóteles hace consistir la beatitud, esto es, la vida perfecta, en el ejercicio teórico, en el pensar, siento que dentro de mí la irritación perfora el respeto hacia el Estagirita. Me parece excesivamente casual que Dios, símbolo de todo movimiento cósmico, resulte un ser ocupado en pensar sohre el pensar. Este afán de divinizar el oficio y el menester que cumplimos sobre la tierra, este prurito de no contentarse cada cual con lo que es, si esto que es no parece lo mejor y lo sumo, se me antoja un resto de la política que perdura hasta en las más altas dialécticas. Aristóteles quiere hacer de Dios un profesor de filosofía en superlativo (pp. 19-20). 
Para Husserl, Schutz, Garfinkel, Sartre, y los etnometodólogos, las cosas no son tan diferentes como las disputas rituales entre subjetivistas y objetivistas parecen mostrar: si Schutz argumentaba que *...el problema principal de las ciencias sociales" era "elaborar un método para abordar de manera objetiva el sentido subjetivo de la acción humana", y llamaba a la construcción de a...objetos de pensamiento en las ciencias sociales* que fueran "compatibles con los objetos del pensamiento de sentido común constituidos por los hombres en la vida cotidiana.... ${ }^{18}$, y si Husserl, maestro de etnometodólogos, hallaba en un yo recogido sobre sí mismo, desinteresado y distanciado del mundo, la posibilidad de acceder universalmente a esa corriente de comunicación y sentido subjetivos ${ }^{19}$, bien poco se han esforzado por esclarecer en qué condiciones es posible practicar esa comunión transcendental que se parece más a una declaración de intenciones que a una posibilidad real. Desde la paradoja platónica de la ultramundaneidad, que quería que el gobierno de las cosas terrenales estuviera en manos de aquellos más alejados de las cosas terrenales porque, de otra manera, el gobierno estaría en manos de personas demasiado apegadas a las cosas terrenales y, por lo mismo, demasiado interesadas en sus propios intereses, se ha reproducido constantemente a lo largo de la historia la idea de que sólo el desapego y el desentendimiento procurarian la perspectiva indispensable para obtener un conocimiento justo de lo observado, aunque nadie, nunca, parece haberse detenido a pensar por el tipo de condiciones que habría que reunir para obtener esa mirada distante y si, una vez agrupadas, esas condiciones no constituirían fundamento suficiente para sostener y crear una condición o grupo social particular, y si, por último, esa percepción retirada de la realidad social no sería, entonces, la prerrogativa de un grupo social privilegiado cuyas condiciones económicas, sociales, culturales y simbólicas les habría permitido poner lo suficientemente a distancia toda clase de necesidades como para adquirir esa exquisita percepción

18 Alfred SchiTz, "El sentido común y la interpretación científica de la acción humana", pp. 35-70, El problema de la realidad social (Buenos Aires: Amorrortu Editores, 1974, 326 p.). Complementarias, son las siguientes obras: Alfred S..H1:TZ, Estudios sobre teoria social (Buenos Aires: Amorrortu Editores, 1974, 277 p.); Edmund Hissfrri, Cartesianische meditationen und Pariser Vortnge (La Haya: Martinus Nijhoff, Husserliana, vol. 1, 1960); Harold Garfinkel, Studies in etbnomethodology (Cambridge: Polity Press, 1967, 288 p.); A. Cotton, La etnometodología (Madrid: Cátedra, 1988, 141 p.).

19 Edmund Hussert, 1960, op. cit.: *En primer lugar, quien quiera llegar a ser seriamente filósofo, debe, en un momento de la vida, retirarse en sí mismo y buscar en sí derribar todas las ciencias sobre las que ya tiene datos para poder reconstruirlas. La filosofia es una asunto completamente personal del sujeto que filosofa. Se trata de una sapientia universalis, es decir, de un saber suyo que contínuamente aspira a lo universal, de un saber por otra parte genuinamente científico que el filósofo puede desde el comienzo y en cualquier momento justificar absolutamente a base de sus principios absolutamente fundados- (p. 4). 
de las cosas sociales. El hombre que descubre el subjetivismo, dispuesto a enfrentarse renovadamente al mundo en cada ocasión como si no existieran unas condiciones previas en las que estuvieran inscritas, a manera de potencialidad, las futuras elecciones, actitudes, percepciones, acciones, no es sino el epítome del propio científico subjetivista, poco dado a admitir o a reconocer la deuda sociológica de su entendimiento.

Las afinidades entre las corrientes de pensamiento objetivista y subjetivista son mucho más profundas que sus discrepancias aparentes, porque en cualquiera de ellas está trabajando un inconsciente epistemológico común que les lleva a aceptar como evidentes aquellas prenociones propias de la condición del intelectual que arrojarán sobre cualquiera de los objetos que observen trastocando la naturaleza del objeto. Vicio común de, aun llegando a analizar genéticamente el proceso de formación de la inteligencia o de las "clases" sociales, permanecer al abrigo de toda autorreflexión que pudiera poner al descubierto los cimientos sobre los que se basa la inteligencia que alcanza del mundo esa clase social.

El rubicón que aun debe rebasar la ciencia social, viene a hacerse ahora evidente, no se levanta sobre discrepancias epistemológicas, sino sobre resistencias sociales: igual que todo indígena se rebela contra la brutalidad reductora del observador foráneo que al no compartir las claves simbólicas de su mundo objetiva su experiencia desencantándola, el científico social se subleva ante la sola idea de que resulte posible objetivar su capacidad, aparentemente incuestionable, de objetivación, que se aireen los obstáculos sociales que en forma de adhesiones y lazos preconscientes, impiden hacer una ciencia legítima, que se le recuerde que las categorías de su entendimiento requieren, simplemente para existir, de unas condiciones objetivas particulares que no les son dadas a todos y que si, en cualquier caso, se insiste en hacerlas pasar por las únicas categorías de entendimiento posible, se acabará haciendo una ciencia de la relación del científico con el objeto y no una ciencia de la manera en que se construyen los objetos.

Como dice el prefacio de El sentido práctico, "el progreso en el conocimiento supone, en el caso de la ciencia social, un progreso en el conocimiento de las condiciones del conocimiento" ${ }^{20}$, y eso requiere, sin duda, objetivar la objetivación, plantear, como dice en otra parte ${ }^{21}$, el análisis sociológico de la producción del productor para delatar los límites de la objetividad, los errores inherentes a la postura del intelectual y a la posición del erudito que se deslizan perturbadoramente en su relación

\footnotetext{
20 Pierre Bol'kitri, El sentido prä́tico (op. cit.), p. 13.

2! Pierre Botrimin, Objetivar al sujeto objetivante”, pp. 98-101. Cosas dicbas (Barcelona: Gedisa, 1988,200 p.)
} 
con los objetos ${ }^{22}$. Para decirlo de una vez, esta parte de la obra de Bourdieu bien podría titularse Nueva Crítica del Juicio, Crítica a la clásica Crítica del Juicio, o, más acorde con los deseos del autor, Critica vulgar de la Critica pura del juicio. No se trata, ni mucho menos, de un lujo prescindible o de un confuso entretenimiento, sino de una necesidad primordial e inaplazable: la crítica social del juicio del intelectual, la vigilancia epistemológica permanente, el obstinado retorno a los mismos objetos como procedimiento para darse otras tantas oportunidades de controlar los supuestos inefables de la relación sujeto/objeto, son el medio privilegiado - ya que la sociología misma es un instrumento de análisis extremadamente poderoso que puede permitir "a cada uno comprender mejor lo que es, dándole una comprensión de sus propias condiciones sociales de producción y de la posición que ocupa en el mundo social" ${ }^{23}$ - a través del que el científico social puede desvelar la clase de intereses indecibles que le unen al objeto elegido para estudio, el tipo de afectos que le hacen darse así mismo por proyecto intelectual un determinado tipo de objetos y no otro, la especie de vinculaciones previa a toda toma de posición explícita respecto del objeto que determina completamente la posición explícita que se toma respecto del objeto.

El progreso de la razón requiere tomar la propia condición como objeto de estudio inicial: paradójicamente, cuanto más "científica" u "objetiva" se vuelve la antropología, cuanto más se toma así misma por objeto primero de estudio descubriendo los principios específicos de su

22 En "Introduction a la socioanalyse". Actes de la Recherche en Sciences Sociales, núm. 90 (1991). pp. 3-5, dice Pierre Bourdieu: -El sociólogo digno de ese nombre no puede ignorar que lo propio de su punto de vista es ser un punto de vista sobre un punto de vista. No puede reproducir el punto de vista de su objeto, y constituirlo como tal al resituarlo en el espacio social, más que a partir de ese punto de vista tan singular... donde hace falta que se sitúe para estar en condiciones de aprehender todos los puntos de vista posibles o 'vivir todas las vidas', como diria Flaubert. Es en la medida en que es capaz de objetivarse asi mismo, que puede, desde el lugar que le es asignado inexorablemente en el espacio social dirigir su pensamiento al lugar donde se encuentra situado su objeto y recoger asi su punto de vista, es decir. comprender que si él estuviera, como decimos, en su lugar, se comportaría y pensaría sin duda como él. (p. 5). Muy claramente también se refiere al mismo problema en Objetivar el sujeto objetivante" (op. cit.): "El hecho de que. como lo he dicho al comenzar, me hubiera dado por proyecto casi consciente, desde el origen, estar atento al objeto, pero también al trabajo sobre el objeto, me ha protegido, creo, contra este error. Lo que queria hacer, era un trabajo capaz de escapar tanto como fuera posible a las determinaciones sociales gracias a la objetivación de la posición particular del sociólogo (dada su formación, sus títulos, sus diplomas, etc.) y a la toma de conciencia de las probabilidades de error inherentes a esta posición. Sabía que no se trataba simplemente de decir la verdad de ese mundo sino de decir también de ese mundo que era el lugar de una lucha para decir la verdad de ese mundo: que se trataba de descubrir que el objetivismo por el cual yo había comenzado, y la tentación que encerraba de aplastar a los competidores al objetivarlos, eran generadores de errores. y de errores técnicos" (p. 100).

«3 Pierre Bot:rotrt, Objetivar el sujeto objetivante», op. cit., p. 101. 
racionalidad y las alteraciones aberrantes a que somete a sus objetos cuando no lo hace, más relevante se hace políticamente, al menos como herramienta negativa, como un escudo contra todas las formas de dominación y mistificación simbólicas que nos privan rutinariamente de convertirnos en verdaderos agentes políticos al hacernos pasar la pura y simple dominación simbólica por conocimiento puro y objetivo ${ }^{24}$.

\section{LA CONSTRUCCIÓN PRÁCTICA Y COTIDIANA DEL JUICIO}

En aquel excepcional artículo que bajo el título de "Contribución al estudio de las representaciones colectivas" escribieron originalmente en 1903 Emile Durkheim y Marcel Mauss ${ }^{25}$, se encuentran las claves del

24 Es esto lo que separa a Bourdieu, dicho sea de paso, de absolutistas del modernismo a la manera de Habermas o Savater, que despreocupados de interrogarse por la diversidad de las condiciones de producción de las categorías del entendimiento, ejercen un absolutismo basado en la ingenua creencia de que todos han de compartir las mismas creencias surgidas de una condiciones de producción del entendimiento excepcionalmente particulares; y es lo que lo separa de retóricos nihilistas o deconstructivistas desencantados, a la manera de Derrida o Rabinow, que esgrimiendo el argumento de la pasada (incluso presente) intolerancia logocéntrica y etnocéntrica del pensamiento eurocéntrico, retornan a formas del más puro desorden y anarqứa positivista.

Por otra parte, la producción bibliográfica de Pierre Bourdien a este respecto, es abundantísima. Tomaremos algunos de sus títulos principales: "Champ intellectuel et projet créateur", Les Temps Moderns, Problèmes du structuralisme, núm. 246 (1966), pp. 865-906; "Champ du pouvoir, champ intellectuel et habitus de classe", Cabiers de Recherches de l'Ecole Normale Supérieure, núm. 1 (1971), pp. 7-26; «Méthode scientifique et hiérarchie sociale des objets", Actes de la Recherche en Sciences Sociales, núm. 1 (1975), pp. 4-6; "Les catégories de l'entendement profesoral., Actes de la Recherche en Sciences Sociales, núm. 3 (1975), pp. 68-93; .The specificity of the scientific field and the social conditions of the progress of reason", Social Science Information, XIV, núm. 6 (1975), pp. 19-47; "Le champ scientifique,, Actes de la Recherche en Sciences Sociales, núm. 2-3 (1976), pp. 88-104; -Les intellectuels sont-il hors jeu?", Questions de sociologie, op. cit., pp. 61-66; „Comment libérer les intellectuels libres?", Questions de sociologie, op. cit., pp. 67-78; Homo Academicus (Paris: Les Editions de Minuit, 1984); aLe hitparade des intellectuels français, ou qui sera juge de la légitimié des juges?., Actes de la Recherche en Sciences Sociales, núms. 52-53 (1984), pp. 14-15; con C. DUVERLIE, "Esquisse d'un projet intellectuel: entretien avec Pierre Bourdieu. The French Review, vol. 61, núm. 2 (1987), pp. 194-205; "Towards a reflexive sociology. A workshop with Pierre Bourdieu", Sociological Theory, vol. 7, núm. 1 (1989), pp. 1-72; -For a socio-analysis of intellectuals: on Homo Academicus, Berkeley Joumal of Sociology, XXXIX (1989), pp. 1-29; *The scholastic point of view., Cultural Anthropology, 5, núm. 4 (1990), pp. 380-391; „Pour une realpolitik de la raison" (entretien avec W. Hiromatsu et H. Imamura), Gendai Shiso, mars (1990), pp. 182-203; "El sociólogo partero. Conocer las causas del malestar social que no se expresa a la luz del día., El País, 5 de julio de 1990, p. 12.

${ }^{25}$ El artículo se encuentra publicado en Marcel Marss, Institución y culto. Representaciones colectivas y diversidad de civilizaciones, Obras II (Barcelona: Barral Editores, 1971, 435 p.), pp. 13-73. 
trabajo de Pierre Bourdieu, y esto es así, entre otras razones, porque en aquel artículo se encuentra claramente definido el cometido y objeto principal de la antropología: si hay un objeto propiamente antropológico, como se encarga de mostrarnos su razonamiento, aunque paradójicamente, desde entonces, haya recibido muy escasa atención, ese es el del análisis de la construcción del juicio, el del estudio del proceso que lleva a cada agente a incorporar las estructuras sociales correspondientes a la posición que ocupa en el espacio social, en forma de disposiciones perceptivas, cogitativas y activas, expresadas en los acontecimientos cotidianos más diversos, en la selección de los atributos que deben formar parte de su identidad.

Con ese aire de antikantismo sociológico que inspira aquella pieza maestra, podemos leer:

Nada nos autoriza a suponer que nuestro espíritu, al nacer, lleva automáticamente dentro de sí el prototipo del cuadro elemental de toda clasificación...Las mismas expresiones de las que nos servimos para caracterizarle autorizan la presunción de que todas estas nociones lógicas tienen un origen extralógico... Estos hechos inclinan a conjeturar que el esquema de la clasificación no es un producto espontáneo del entendimiento abstracto, sino que resulta de una elaboración en la cual han entrado todo tipo de elementos extraños... Lejos de inclinarnos a admitir como una evidencia que los hombres clasifican naturalmente, a través de una especie de necesidad interna de su entendimiento individual, por el contrario, debemos preguntarnos qué es lo que ha podido llevarlos a disponer sus ideas bajo estas formas y dónde han podido encontrar el plan de esta notable disposición ${ }^{20}$.

Esta verdadera duda radical que desmorona toda forma de sustancialismo pertinaz y antirreflexivo ${ }^{27}$, estaba basada, como es sabido, en el análisis de la construcción de las categorías de pensamiento y clasificación de los aborígenes australianos y de los confeccionadores del horóscopo chino: como ha sucedido a lo largo de la historia de las culturas, las

26. Emile Durкhғiм y Marcel Mauss, op.cit., p. 17.

27 Creemos, sin temor a equivocarnos, que este profundo antisustancialismo, que es conciencia extremadamente sensible a los efectos políticos de la reificación de cualquier posición y opinión, le viene a Botiruifu por varias vías, especialmente por la nietzscheana. En La genealogía de la moral, op.cit., p. 139, leemos: * partir de ahora, señores filósofos, guardémonos mejor, por tanto, de la peligrosa y vieja patraña conceptual que ha creado un 'sujeto puro del conocimiento, sujeto ajeno a la voluntad, al dolor, al tiempo', guardémonos de los tentáculos de conceptos contradictorios tales como 'razón pura', 'espiritualidad absoluta', 'conocimiento en sí'... Existe únicamente una perspectiva, únicamente un 'conocer' perspectivista; y cuanto mayor sea el número de afectos a los que permitamos decir su palabra sobre una cosa, mayor sea el número de ojos, de ojos distintos que sepamos emplear para ver una misma cosa, tanto más completo será nuestro concepto de ella, tanto más completa será nuestra objetividad. Pero eliminar en absoluto la voluntad, dejar en suspenso la totalidad de los afectos, suponiendo que pudiéramos hacerlo: ¿cómo?, ¿es que no significaría eso castrar el intelecto?. 
diferencias de naturaleza social (clanes, secciones, fratrías, grupos, clases), porque de ningún otro sitio pueden provenir las diferencias, se proyectaban en diferencias de naturaleza natural (accidentes geológicos, cosmológicos, biológicos) para que, bajo este aspecto definitivo por ser escasamente sospechoso de poseer un origen humano, quedaran concluyentemente establecidas las divisiones sociales que eran, a la vez, divisiones mentales. Además, hombres de fin de siglo que nos creemos lejos del pensamiento mitológico, procedemos, en lo que respecta a la producción de las categorías del entendimiento, como nos recuerdan Durkheim y Maus, de la misma manera que hicieron nuestros antepasados primitivos. Es esto lo que extraemos de la lectura de estos párrafos extensamente citados:

Lo que caracteriza a éstas últimas [las clasificaciones] es que las ideas aparecen organizadas en ellas sobre un modelo que proporciona la sociedad (p. 33) ...las clasificaciones primitivas no constituyen singularidades excepcionales, sin analogía con las que están en uso en los pueblos más cultivados; por el contrario, parecen remitirse sin solución de continuidad a las primeras clasificaciones científicas... Cabe pensar, por lo tanto, que las condiciones de que dependen estas clasificaciones tan antiguas no han dejado de representar un papel importante en la génesis de la función clasificadora en general. Ahora bien, de todo este estudio se desprende que dichas condiciones son de naturaleza social (p. 68)... han sido las relaciones sociales entre los hombres las que han servido de base a las relaciones lógicas entre las cosas... Hemos visto, efectivamente, que tales clasificaciones han sido modeladas sobre la organización social más próxima y fundamental. Incluso, la expresión es insuficiente. La sociedad no ha sido simplemente un modelo sobre el cual haya trabajado el pensamiento clasificador; sus propios cuadros han servido de cuadros al sistema. Las primeras categorías lógicas han sido categorías sociales; las primeras clases de cosas han sido clases de hombres en los que se integraban dichas cosas. Los hombres han agrupado idealmente a las otros seres porque previamente estaban ellos agrupados y se veían así mismos bajo la forma de grupos; los dos modos de agrupamiento han empezado confundiéndose para terminar siendo indistinguibles (p. 69).

La conclusión a la que llegaba aquel trabajo, que ilumina hasta el día de hoy el pensamiento antropológico y que, de haber seguido su luz, hubiera ahorrado tanto ensimismamiento intelectual, era la que no nos resistimos a reproducir:

A través de este ejemplo, puede verse con qué luz ilumina la sociología la génesis $y$, por consiguiente, el funcionamiento de las operaciones lógicas. Lo que nosotros hemos intentado hacer para llegar a la clasificación, podría ensayarse igualmente respecto de las otras funciones o nociones fundamentales del entendimiento. Ya hemos tenido la ocasión de indicar, al hilo de nuestro análisis, cómo incluso ideas tan abstractas como las de tiempo y de espacio. en cada momento de su historia, están en relación estrecha con la organización social correspondiente. El mismo método podría, asimismo, ayudar a comprender la manera cómo se han formado las ideas de causa, de sustancia, las diferentes formas de razonamiento, etc. Todos estos problemas, que esgrimen metafísicos y psicólogos desde hace tiempo, al fin serán 
liberados de las reiteraciones en las que se hallan trabados, el día en que sean planteados en términos sociológicos. Al menos, ahí existe una vía nueva que merece la pena ensayar ${ }^{28}$.

Si Bourdieu toma al pie de la letra las recomendaciones de los maestros, librándose de las ilusas e inacabables discusiones de psicólogos y metafísicos, condenados a reproducir la representación de la práctica o la acción de los agentes en términos dicotómicos (libertad/sumisión; autonomía/servidumbre, etc.) por desestimar su fundamento sociológico, y si, como recomendaban también los predecesores, traslada ese impulso sociológico al análisis de la génesis de las diferentes formas de razonamiento, vemos bien cómo ese plan se complementa con las exigencias del socioanálisis del propio juicio: el estudio cabal de las prácticas de los agentes de cualquier sociedad y la reinstauración sensata del individuo en la teoría social, pasan por la objetivación de la relación del antropólogo con el objeto para que el discurso sobre el objeto no sea una simple proyección de una relación inconsciente con el objeto que obligue a éste a ser más o menos (excesivamente emancipado o excesivamente mecánico) de lo que realmente es.

Erwin Panofsky, con su Arquitectura Gótica y Pensamiento Escoláticớr, influyó también de una forma definitiva en la conformación del pensamiento de Bourdieu a este respecto: persuadido del poder conformador de la realidad que tienen los habitos mentales, indagó en la relación establecida entre escolástica y arte gótico para llegar a la conclusión de que tal conexión resultaba "más concreta que un simple 'paralelismo' y no obstante más general que 'esas influencias individuales' (y también tan importantes) que los consejeros eruditos ejercen sobre los pintores, los escultores o los arquitectos" ${ }^{30}$. Así las cosas, Panofsky coincidía con

28 E. Dirkhifim y M. MAI's৬, op. cit., p. 73.

$\because$ Erwin PaNofisk, A Gothic Architecture and Scholasticism (Latrobe Pensilvania: SainVincent-College, 1957); Arquitectura Gótica y Pensamiento Escolástico (Madrid: Las Ediciones de La Piqueta, 1986, 140 p.). No en vano, el segundo trabajo importante publicado por Bourdieu fue la traducción y edición al francés de esta obra: Architecture gotbique et pensée scolastique (Paris: Les Editions de Minuit, 1967).

E. PANOFsKy, op. cit., p. 31. La cita puede completarse con el siguiente texto: asi bien resulta difícil, cuando no imposible, aislar una fuerza formadora de hábitos entre muchas otras e imaginar sus canales de transmisión, el periodo que va aproximadamente desde 1130-1140 hasta 1270 y la zona que abarca "ciento cincuenta kilómetros alrededor de París constituyen una excepción. En esta restringida área la escolástica poseía el monopolio educativo: en líneas generales la formación intelectual había pasado de las escuelas monásticas a instituciones más urbanas que rurales, más cosmopolitas que regionales $y$, por así decirlo, solamente semieclesiásticas, $o$, lo que es lo mismo, había pasado a escuelas catedraliceas, universidades y studia de las nuevas órdenes mendicantes (casi todas fundadas en el siglo xiil) y cuyos miembros desempeñaban un papel cada vez más importante en el seno de las universidades mismas. A medida que el movimiento escolástico, preparado por la enseñanza de los 
Durkheim y Mauss en que existía una fuerza formadora de hábitos perceptivos, cogitativos y activos de origen social que, a falta de una denominación mejor, podía llamarse principium importans ordinem ad actum $^{31}$, "principio que regula el acto".

Con estos antecedentes, Bourdieu toma el problema de la práctica como un problema coincidente con el de la formación del juicio y con el de su uso estratégico cotidiano: el problema radica en comprender la manera en que las estructuras sociales se incorporan en forma de estructuras mentales que se convierten en disposiciones (del habla, del cuerpo, del gusto) transponibles a los ámbitos más variados de la vida social, capaces de producir comportamientos novedosos en situaciones cambiantes ${ }^{32}$ y que, como marcas de pertenencia a una clase determinada, avisan a sus poseedores de la deseabilidad o indeseabilidad de entrar en contacto con agentes de disposiciones diferentes para reproducir o alterar su posición social y su disposición mental. Las estructuras sociales particulares, en forma de estructuras estructuradas, se asociarian a los agentes en forma de estructuras estructurantes, es decir, lo social se haría segunda naturaleza no de una forma mostrenca y pasiva, sino generativa y activa, inscribiendo en el cuerpo, el habla y los hábitos de los agentes las disposiciones "propias" de la condición social a la que se pertenece, por tanto, también, a la vez que sentido de lo deseable y ambicionable, sentido exacto de lo indeseable y lo impensable solidario con los límites de la propia condición. Bourdieu condensa esta teoría del conocimiento y la acción, en el concepto de habitus, término que no sería más que ese sistema de disposiciones adquirido mediante la anexión de unas estructuras y unas condiciones objetivas, que es duradero porque su inculcación ha sido tarea insensible de la tradición y su aprehensión ha requerido de una exposición más o menos larga a los efectos de esas condiciones limitativas; que es trasladable porque allí donde se oriente intentará encontrar las mismas condiciones que lo produjeron; que es

benedictinos y lanzado por Lanfranc y Anselmo de Bec, se desarrollaba y extendía gracias a los dominicos y a los franciscanos, el estilo gótico, preparado en los monasterios benedictinos y lanzado por Suger de Saint-Denis, alcanzaba su apogeo en las grandes iglesias urbanas(p. 32).

"Término recogido de Sto. Tomás de Aưuino, Summa Theologiae, 1-1I, q. 49, art. 3, C. Se encuentra en la p. 31 de Arquitectura Gótica y Pensamiento Escolástico.

12 Es esto lo que le aleja, por ejemplo, de autores como Noam Cномsкr (por ejemplo, el de El lenguaje y el entendimiento, Barcelona: Seix Barral, 1986 [1968], 317 p.) que, aunque preocupados por la generatividad del comportamiento, se prohiben a sí mismos avanzar en su conocimiento porque renuncian desde un principio a establecer los fundamentos sociológicos del comportamiento sosteniendo una especie de comunismo lingüistico que proporciona la ilusión de una competencia solidariamente repartida entre todos los hablantes de una comunidad lingüistica, o, lo que es lo mismo, una competencia cognitiva similar entre todos los miembros de una cultura determinada. 
generativo porque producirá comportamientos objetivamente ajustados a situaciones perpetuamente renovadas; y que produce, por tanto, prácticas objetivamente unificadas, distinguibles por su estilo particular, en cualquiera de los campos que intervenga. En sus propias palabras, los esquemas del babitus son,

...formas de clasificación originarias que deben su eficacia propia al hecho de que funcionan más allá de la conciencia y el discurso, luego fuera de las influencias del examen y del control voluntario: orientando prácticamente las prácticas, esconden, lo que se denominaría injustamente unos valores en los gestos más automáticos o en las técnicas del cuerpo más insignificantes en apariencia, como los movimientos de las manos o las maneras de andar, de sentarse o de sonarse, las maneras de poner la boca al comer o al hablar, y ofrecen los principios más fundamentales de la construcción y de la evaluación del mundo social, aquellos que expresan de la forma más directa la división del trabajo entre las clases, las clases de edad y los sexos, o la división del trabajo de dominación, en unas divisiones de los cuerpos y de las relaciones con el cuerpo que toman más de un rasgo, como para darle las apariencias de lo natural, de la división sexual del trabajo y a la división del trabajo sexual. Dominio práctico de las distribuciones, que permite sentir o presentir las probabilidades de futuro o de no futuro que existen, e, inseparablemente, lo que conviene o no conviene a un individuo que ocupa tal o cual posición en el espacio social, el gusto, al funcionar como una especie de sentido de la orientación social (sense of one's place), orienta a los ocupantes de una determinada plaza en el espacio social hacia las posiciones sociales ajustadas a sus propiedades, hacia las prácticas o los bienes que convienen -que le "van- a los ocupantes de esa posición..."

33 Pierre Bourdiev, La distinción, op. cit., pp. 477-478. Esta reflexión, como todas aquellas referentes al cuerpo como depósito oscuro de la memoria, como naturaleza socializada a través del habitus, es deudora en buena parte de la Phenomenologie de la perception de Maurice Merleatl-Ponty (Paris: Gallimard, 1992 [1945], 531 p.). Si bien por su carácter fenomenológico el trabajo de éste último autor se despreocupa por completo de la génesis social de las condiciones de posibilidad de la percepción, muchas de sus observaciones han pasado a enriquecer la obra de Boukiffu. Esta primera hace referencia a la necesidad de pensar la acción a partir de un principio único que reelabora la experiencia bruta a partir de la capacidad innata e irrenunciable de estructurar cualquier experiencia previamente estructurada: "Desde el punto de vista de la existencia, estos dos hechos, que la inducción cientifica se limita a yuxtaponer, se reunen interiormente y se comprenden sobre una misma idea. Si el hombre no debe ser encerrado en... un medio sincrético donde el animal vive como en estado de éxtasis, si debe tener conciencia de un mundo como razón común de todos los medios y teatro de todos los comportamientos, hace falta que entre él mismo y eso que llama su acción se establezca una distancia, hace falta que, como decía Malebranche, los estímulos de fuera no le toquen mas que con 'respeto', que cada situación momentánea cese de ser para él la totalidad de lo que es, cada respuesta particular de ocupar todo su campo práctico, que la elaboración de esas respuestas, en lugar de constituirse en el centro de su existencia, pasaran a la periferia y que, en fin, las mismas respuestas no exijan más cada vez que una toma de posición singular y sean modeladas de una vez por todas en su generalidad. (p. 103).

El cuerpo se establece como centro de esta unidad de acción, como naturaleza que, al socializarse, hace pasar por disposiciones y hábitos naturales lo que no son sino disposiciones y habitos sociales: •El cuerpo es el vehículo del ser en el mundo, y tener un cuerpo es para un viviente unirse a un medio definido, confundirse con ciertos proyectos y comprometerse 
Si es cierto, como hemos desarrollado en la nota anterior, que Bourdieu debe parte de sus ideas sobre la socialización del cuerpo a los análisis de Merleau-Ponty, y que, gracias a él, captó hasta que punto el trabajo sobre el cuerpo consigue un eco inedeleble, inmediato e infraconsciente sobre las prácticas, no sólo del cuerpo, sino del ser humano en su conjunto, también es verdad que allí donde acaba la tarea de Merleau-Ponty, comienza la de Bourdieu: según el primero, "no podemos hacer la economía de esta potencia irracional que crea las significaciones y que las comunican ${ }^{34}$, refiriéndose a su incapacidad para hallar principios que dieran cuenta satisfactoria de la lógica, entre otras cosas, de las disposiciones corporales, cuestión que queda en vías de resolución, de acuerdo con el segundo, cuando se establecen las condiciones divergentes de formación de la percepción ${ }^{35}$ que es, antes que nada, percepción del propio cuerpo y de lo que le conviene o le incomoda, lo que es lo mismo, lucha por el uso legítimo del cuerpo, último refugio de toda lucha social ${ }^{36}$. Lo que es crucial señalar es que no nos es posible estudiar

con ellos contínuamente (p. 97)... La unión del alma y el cuerpo no está sellada por un decreto arbitrario entre dos términos exteriores, uno objeto, otro sujeto. Se realizan a cada instante en el movimiento de la existencia (p. 105)... La adquisición del hábito [habitude] como transformación y renovación del esquema corporal ofrece grandes dificultades a los filósofos clásicos, todos dispuestos a concebir la síntesis como una síntesis intelectual. Es cierto que ésta no es una asociación exterior que reune en el hábito los movimientos elementales, las reacciones y los estímulos. Toda teoría mecanicista choca con el hecho de que el aprendizaje es sistemático: el sujeto no agrupa los movimientos individuales a los estímulos individuales, sino que adquiere el poder de responder con un cierto tipo de soluciones a una cierta forma de situaciones, donde las situaciones podrán diferir ampliamente de un caso al otro. los movimientos de respuesta podran ser confiados tanto a un órgano ejecutor, como a otro, situaciones y respuestas se parecerán en los diferentes casos mucho menos por la identidad parcial de los elementos que por la comunidad de sus sentidos (p. 166)m.

"M. MFRIFAl-PONT1, op. cit., p. 221.

"Pierre Bol:kinet, "Pour une sociologie de la perception", Actes de la Recherche en Sciences Sociales, 40, novembre (1981), pp. 3-9.

"Son numerosos los trabajos que Bol'riml ha dedicado a algo que, si no se integra dentro de su plan general de investigación, bien podría parecer que permanecen al margen del resto. Nos referimos a sus investigaciones sobre "Antropología del deporte", o, más bien, sobre el tipo de práctica deportiva que cada una de las clases sociales elige para obtener un cuerpo determinado que le sirva en los enfrentamietos por el tipo de cuerpo legítimo, el uso legítimo del cuerpo, y la práctica legítima del deporte elegido. En "Comment peut-on être sportif?., Questions de sociologie (Paris: Les Editons de Minuit, 1984, 277 p.), pp. 173-195, dice: *De hecho, fuera de toda búsqueda de la distinción. es la relación con el cuerpo propio, como dimensión privilegiada del habitus, la que distingue a las clases populares de las clases privilegiadas de la misma manera que, al interior de ellas mismas, distingue a las fracciones separadas por todo el universo de un estilo de vida. Así, la relación instrumental con el cuerpo propio que las clases populares experimentan en todas las prácticas tenga al cuerpo por objeto o apuesta, regimen alimentario o cuidado de belleza, relación con la enfermedad o cuidado de salud, se manifiesta también en la elección de deportes que demandan una gran inversión de 
las prácticas deportivas, la relación que se establece con el propio cuerpo a través del deporte elegido, sin estudiar todo un conjunto de consumos solidarios, como pueden ser el consumo alimentario o el consumo de ocio en general, lo que, en última instancia, nos lleva de vuelta al centro del problema: debe existir un principio capaz de ordenar los actos de los agentes, principio generativo de percepción, pensamiento y acción que aprehendido prácticamente es utilizado en la práctica para reproducir o mejorar, en la medida de lo posible, sus propias condiciones de producción.

Para continuar avanzando debemos tener en cuenta que el concepto de habitus, ese principio ordenante de las prácticas transponible a cualquiera de los ámbitos imaginables de la vida cotidiana, capaz de enfrentarse creatiavamente a toda nueva situación, no tiene sentido aisladamente ni es equiparable a ningún término sencillo, cosa que olvidan la mayoría de los comentaristas. El concepto de habitus sólo cobra sentido cuando se lo pone en relación con los de campo, illusio y doxa ${ }^{3-}$. Por campo debemos entender cualquier institución históricamente construida (sea el campo de la filosofía, de la producción artística, de la política, de la religión, del deporte, etc.) dotada de un conjunto de leyes de funcionamiento y normas de juego particulares, que es, antes que nada, un campo de fuerzas, esto es, un conjunto sistemático de diferencias que por el hecho de ofrecer objetivadas una suma de desigualdades a un conjunto de agentes que están predispuestos previamente a percibirlas de manera discrepante, a interesarse por ellas de modo distinto, y a usarlas de forma desemejante, parece poder generar su propio interés. Digamos que el concepto de campo, en este sentido, sustituye al anquilosado concepto de estructura, porque ésta no es, en todo caso, más que el producto objetivado de las luchas históricas entre agentes tal como se pueden captar en un momento determinado del tiempo, cuestión que exige disponer de un concepto dinámico y elástico que nos permita entender

esfuerzo, posiblemente de dolor y de sufrimiento (como el boxeo), y exigen en ciertos casos una puesta en juego del mismo cuerpo, como el motociclismo, el paracaidismo, todas las formas de acrobacia y, en una cierta medida, todos los deportes de combate..." (p. 192). Otros títulos igualmente interesantes, son: "Programa para una sociología del deporte. Cosas dichas (Barcelona: Gedisa, 1988, 200 p.). pp. 173-184; - Remarques provisoires sur la perception sociale du corps, Actes de la Recherche en Sciences Sociales, 14, avril (1977), pp. 51-54; «Pratiques sportives et pratiques sociales». Conférence inaugurale au Congrès International de l'HISPA (Paris, INSEP, 28 mars-2 avril, 1978), Actes du VIIe Congrès International (Paris: INSEP, 1978), tome 1. pp. 17-37; Introduction., Le grand livre du rugby français 1981-1982, (Beleville. Rhône: F.M.T. Editions S.A., 1981), p. 7.; es en La distinción, op. cit., particularmente, donde podremos encontrar el desarrollo completo de estas aproximaciones.

"Pierre Bol'rimel, "The genesis of the concepts of Habitus and Field, Sociocritictsm, Theories and Perspectives, II, núm. 2, décembre (1985), pp. 11-24. 
cómo se transforman las estructuras, que nos permita comprender que no existen estructuras más que por el intermedio de las prácticas y que éstas no existirían si no fuera por la preexistencia de aquéllas ${ }^{38}$. Entre los dos conceptos, habitus y campo, existe una compliøidad ontológica fundamental: el estudio de la génesis del primero en un agente determinado, es inseparable del estudio de la estructura del segundo, por que aquél no se forma sino por intermedio de la posición que se ocupa en el campo, es decir, por el intermedio de la distribución de capitales específicos que hay en cada una de las posiciones del campo y que el agente incorpora en forma de disposiciones perceptivas y activas, y que compromete, de una u otra manera, según le aconseje su posición en el campo y su percepción del mismo, en la transformación misma del campo ${ }^{39}$. Si

38 En Central problems in social theory. Action, structure and contradiction in social analysis (London: MacMillan Education, 1990 [1979], 294 p.), Anthony Giddens hizo que su concepto de doble estructuración (1990: 5) se convirtiera en el centro de su teoría de la estructuración y de la acción (1990: 69). Gidvens vincula explícitamente su primer concepto (1990: 217) al término doble estructuración creado por Bourdif. Ambos pretenden dar cuenta de la inoperancia de mantener escindidos los conceptos de estructura y acción y pretenden, con esas herramientas explicativas, dar cuenta de su carácter inseparable. En lo que respecta a la teoría de la acción, Bourdifu se separa de Gidnens en que éste último no presta atención a la objetivación de su propia posición de observador, con lo que acaban reproduciéndose los problemas que su teoría de la acción pretendía evitar. Con referencia a la bibliografía de campos, puede consultarse: "Quelques propriétés des champs", Questions de sociologie, op.cit., pp. 113-120; "Champ du pouvoir, champ intellectuel et habitus de classe", Scolies, Cahiers de Recherchers de l'Ecole Normale Supérieure, 1 (1971), pp. 7-26; "Genèse et structure du champ religieux", Rerue Française de Sociologie, XII, 3 (1971), pp. 295-334; "Les intellectuels dans le champ de la lutte des classes*, La Nouvelle Critique, núm. 87, octobre (1975), pp. 20-26; "La représentation politique. Eléments pour une théorie du champ politique», Actes de la Recherche en Sciences Sociales, 36-37, février-mars (1981), pp. 3-24; "La champ littéraire. Préalables critiques et principes de méthode*, Lendemains, IX, 36 (1984), pp. 5-20; "Effet de champ et effet de corps", Actes de la Recherche en Sciences Sociales, 59, septembre (1985), p. 73; "Exitet-il une littérature belge? Limites d'un champ et frontières politiques", Etudes de lettres, 4, octobre-décembre (1985), pp. 3-6; ,Le champ religieux dans le champ de production symbolique», Postfacio en Les nouveausx clercs (Genève: Labor et Fides, 1985, pp. 255-261); "La force du droit. Eléments pour une sociologie du champ juridique,. Actes de la Recherche en Sciences Sociales, 64, septembre (1986), pp. 5-19; "Agrégation et ségrégation. Le champ des grandes écoles et le champ du pouvoir", Actes de la Rechercbe en Sciences Sociales, 69, septembre (1987), pp. 2-50; "Variations et invariants. Eléments pour une histoire structurale du champ des grandes écoles", Actes de la Recherche en Sciences Sociales, 70, novembre (1987), pp. 3-30; "La théorie du champ dans l'espace des possibles théoriques", Gendai Shiso, mars (1990), pp. 204-219; "Le champ littéraire", Actes de la Rechercbe en Sciences Sociales, 89 (1991), pp. 3-46.

19 Una de todas las posibles definiciones que Bourdieu proporciona del concepto campo es la que se encuentra en "Quelques propriétés des champs*, op. cit., p. 114: "La estructura del campo es un estado de las relaciones de fuerza entre los agentes o las instituciones compromentidas en la lucha o, si lo preferimos, de la distribución del capital específico que, acumulado en el curso de las luchas anteriores, orienta las estrategias ulteriores... Esta estructura, que está al principio de las estrategias destinadas a transformarlo, está ella misma 
esta formulación puede paracer abstracta en exceso, no habría más que volverse hacia la actividad particular de uno mismo, para darse cuenta de la capacidad explicativa de los conceptos: pertenecer, como es el caso, al campo de producción intelectual, campo cuyo funcionamiento es estructuralmente homólogo al de cualquier otro tipo de campo (político, literario, etc.), para romper con la imagen autocomplaciente y autoengañosa de un mundo al margen de las constricciones habituales del mundo social, conlleva, en primer lugar, aceptar un tipo de relaciones de fuerza peculiares que se imponen sobre todos los agentes que entran en el campo y convenir, en segundo, en la existencia de dominantes y dominados, conservadores y vanguardistas, todo en función de un tipo de capital acumulado por medio de un trabajo y unas estretegias específicas que se hace especialmente valioso en este campo, el capital simbólico que, en forma de conocimiento, reconocimiento y consagración, institucionalizados o no, dan derecho a ocupar una u otra posición en ese campo; lo general y singular a la vez en cada campo es que, para que un campo funcione, hace falta que existan apuestas y personas dispuestas a jugar el juego de las apuestas, a admitir la creencia del valor e interés inherente al juego ${ }^{40}$, personas dotadas de un habitus que implica el conocimiento y reconocimiento de las leyes inmanentes al juego, a las apuestas, etc.: por ejemplo, en el campo de producción intelectual, aceptar que las luchas por la dominación tomen la forma eufemizada e incruenta de guerras a propósito de las palabras; asumir las censuras que pesan sobre modos de expresión y temas elegidos; admitir que la acumulación del prestigio intelectual y, por tanto, el poder para hacer un uso particular de ciertas palabras, posee una lógica que obliga a la publicación acelerada de reflexiones aceleradas; reconocer que la consagración de la posición de un autor novel

en juego: las luchas donde el campo es el lugar tienen por apuesta el monopolio de la violencia legítima (autoridad específica) que es característica del campo considerado, es decir, en definitiva, la conservación o la subversión de la estructura de la distribución del capital específicor.

En sLa métamorphose des goûts", Questions de Sociologie, op. cit., pp. 161-172, proporciona una de las visiones más profundas y dinámicas del concepto. En estos tiempos que corren, absurdamente entretenidos en discutir sobre el fin de la historia, como si tan siquiera resultara posible detener el funcionamiento de los campos, el pensamiento de Botiritivi viene a disipar toda duda: ‘Hacer época, es hacer la historia, que es el producto de la lucha, que es la lucha misma; en el momento en que no hay más lucha, no hay más historia. En tanto que hay lucha hay historia, por tanto esperanza. En cuanto no hay más lucha, es decir, resistencia de los dominados, hay monopolio de los dominantes y la historia se detiene. Los dominantes, en todos los campos, ven su dominación como el fin de la historia -en el doble sentido de término y meta-, que no hay nada más allá y se encuentra, por tanto, eternizada. (p. 168).

40 Pierre Bourdifu, sla production de la croyance: contribution à une économie des biens symboliques;, Actes de la Recherche en Sciences Sociales, 13, février (1977), pp. 3-43. 
puede venir de la mano de un prefacio dedicado por un autor consagrado; asumir que la posible incorporación a la institución que fomenta la creencia en el valor del trabajo intelectual, la institución universitaria, puede llevar y exigir años de paciente sometimiento y sosegada resignación en nombre del elevado interés inherente al trabajo intelectual; afirmar, en fin, que el trabajo intelectual es la sublimación de toda otra clase de trabajo.

Una etnografía del campo de producción intelectual, por ejemplo, similar a la que Bourdieu planteó en Homo Academicus ${ }^{41}$, debería definir las apuestas e intereses específicos que son irreductibles e intransferibles a los intereses y apuestas de otros campos y que, desde luego, no son percibidas ni cabalmente valoradas por aquellos que no han sido constituidos para entrar en ese campo: de ninguna manera los reconocimientos, anuencias, rechazos, repudios, inversiones y desinversiones propios del campo de producción intelectual que resultan en un tipo de prácticas determinadas y propias de ese campo, son transparentes e inmediatamente aceptables para los agentes componentes de otros campos. Es a esto a lo que Bourdieu denomina teoría general de la economía de las prácticas, porque la economía y racionalidad de una práctica sólo puede valorarse en referencia al campo en el que se pone en acción esa práctica, en referencia a los beneficios que, en ese campo, puede reportar un tipo determinado de práctica, aunque esa práctica pueda parecer descabellada, desproporcionada o simplemente absurda a los ojos de una persona que no comparte las creencias inherentes a ese campo. Todos los trabajos de Bourdieu a propósito de la lógica del bonor y de las costosísimas inversiones que en términos de tiempo, energía y dinero puede costar el buen nombre, sea el ejemplo prototípico del potlach sea la lucha por la precedencia social en la kabilia, ponen en evidencia que las prácticas que exige la economía del campo son, paradójicamente, antieconómicas en términos de la racionalidad económica contemporánea: el mantenimiento de los lazos sociales que habrán de procurar múltiples retornos en forma de ayudas y apoyos de todo tipo en economías previas a las economías de mercado ${ }^{+2}$, reclama un trabajo de constante vigilancia y atención que

1 Pierre Bontmit, Homo Academicus (Paris: Les Editions de Minuit, 1984).

12 Karl Polany, uno de los autores que Boiriner: siempre reivindica como precursor de los estudios sobre la diferenciación lógica de las economías premercantiles y mercantiles, aseguraba en La gran transformación. Crítica del liberalismo económico (Madrid: Ediciones de la Piqueta, 1989 [1944], 466 p.): “...economia de mercado supone un sistema autorregulador de mercados. Para emplear términos un poco más técnicos, se trata de una economía gobernada por los precios del mercado y únicamente por ellos. Sólo en este sentido se puede decir que un sistema de este tipo, capaz de organizar la totalidad de la vida económica sin ayuda o intervención exterior, es autorregulador. Estas someras indicaciones deberían bastar para mostrar la naturaleza absolutamente inédita de esta aventura en la historia de la raza humana (p. 83)... La historia y la etnografía han mostrado la existencia de distintos tipos de economías 
no puede escatimar esfuerzo alguno. No es una paradoja más el hecho de que la economía de mercado acabara imponiéndose y propagándose al economizar y disminuir considerablemente ese trabajo de cuidado intensivo sustituyéndolo por mecanismos de autorregulación, y no es casualidad que durante tanto tiempo hayan permanecido incomprendidos los mecanismos de cambio económico y social, porque al afrontarlos desde la lógica del marginalismo o del marxismo económicos, no se reparaba en que el ingreso en un nuevo campo (aquí, el campo de los intercambios mercantiles y la racionalidad comercial) exige la adquisición de las disposiciones propias de ese campo (aquí, la previsibilidad de las operaciones y de los resultados, la equivalencia entre inversión de esfuerzos y rendimientos obtenidos, la contabilización del tiempo como recurso explotable, la distinción entre tiempo de trabajo y ocio y entre trabajo y desempleo, la conquista de un conjunto de disposiciones solidarias manifestadas en el nuevo estilo de vida, en los habitos de vivienda y consumo, etc.), y exige, de quienes deben estudiar ese cambio de disposiciones y de campo, el análisis de las condiciones objetivas mínimas y necesarias para que pueda darse ese cambio ${ }^{+3}$.

Ninguna adaptación resulta sencilla porque la inercia de la illusio nos lleva a prolongar en una situación en que ya no existen las condiciones en que se produjeron nuestros hábitos perceptivos y activos, las mismas prácticas que hubiéramos puesto en práctica si siguieran existiendo esas mismas condiciones originales: la illusio, concepto que antes relacionábamos con los de campo y doxa, es el sumergimiento en el campo, la adhesión cognitiva y práctica al valor de lo que allí se pone en juego, la reproducción y propagación del sentido y transcendencia de lo que se hace a fuerza de repetirlo, la dificultad de cuestionar la importancia de

que, en su mayor parte, cuentan con la institución de los mercados; sin embargo, ni la historia ni la etnografía han tenido conocimiento de ninguna otra economía anterior a la nuestra que, incluso aproximativamente, estuviese dirigida y regulada por los mercadosn (p. 85).

4) Pierre Botrdtri, Sociologie de l'Algérie, (Paris: P.U.F., Coll. «Que-sais-je», núm. 802; nueva ed. revisada y corregida, 1961); "Guerre et mutation sociale en Algérie., Etudes Mediterranéennes, 7, printemps (1960), pp. 25-37; Travail et travailleurs en Algérie (Paris-La Haye, Mouton, 1963); "La société traditionnelle. Attitude à l'égard du temps et conduite économique, Sociologie du travail, 1, janvier-mars (1963), pp. 24-44; Le déracinement, la crise de l'agriculture tradittionnelle en Algérie (Paris: Editions de Minuit, 1964, con A. Sayad: ed. esp. Argelia entra en la bistoria: Barcelona, Editorial Nova Terra, 1965): "The attitude of the Algerian peasent toward time", en Mediterranean countrymen, Pitt-Rivers, J. (ed) (Paris-La Haye: Mouton, 1964), pp. 55-72; „Paysans déracinés, bouleversements morphologiques et changements culturels en Algérie, Etudes Rurales, 12, janvier-mars (1964), pp.56-94; “Formes et degrés de la conscience du chômage dans l'Algérie coloniale, Manpower and Unemployment Research in Africa, vol. 4, 1, avril (1971), pp. 36-44; Algérie 60, structures économiques et structures temporelles, (Paris: Editions de Minuit, 1977); *Réponse aux économistes- (Paris, Colloque sur the modèle économique dans les sciences sociales, Université de Paris-I, avril 1981), Economies et sociétés, XVIII, 10, octobre (1984). pp. 23-32. 
lo que se realiza a riesgo de paralizar la propia existencia, falta de razones aparentemente sólidas para pervivir ${ }^{44}$. Esta afección cognitiva y existencial a los límites del campo, que no permiten distinguir entre lo ortodoxo y lo heterodoxo porque no existe mas que un .horizonte de prácticas posibles, es la que recibe el nombre de doxa, de experiencia dóxica: todo orden, como señala Bourdieu en Esquisse d'un théorie de la pratique, tiende a producir la naturalización de su propia arbitrariedad, y esto hay que achacarlo menos a medidas institucionales, que al funcionamiento normal de la percepción, que establece los límites de lo deseable, los confines de las esperanzas subjetivas, allí donde las condiciones objetivas en que se formó esa percepción, establezca. La acomodación entre una y otra instancia asegura una solidaridad inquebrantable con el orden establecido, porque al ser las estructuras mentales interiorización de las estructuras sociales, el límite de aquéllas no puede sino ser el límite de éstas ${ }^{45}$. Esta situación es el origen de muchos malentendidos en la teoría sociológica y política: no sólo los comentaristas y los profesionales de la

t Cuestionar la illusio, darle a las costumbres extrañas a nosotros ese aspecto de desatino o disparate que tienen los reportajes periodísticos sobre aspectos puntuales de otras culturas, o esa apariencia de ser un objeto destinado por su rareza a la descodificación que le dan las aproximaciones científicas, es resultado de la posición objetiva que ocupa el observador foráneo: la de aquél que no puede reconocer desde el exterior y desde la diferencia que las inversiones en el juego son siempre ilusiones bien fundamentadas, "experiencias bien fundadas" como decía Durkheim en Las formas elementales de la vida religiosa (Madrid: Akal Editor, 1982 [1912], 423 p., p. 423) a propósito de la práctica religiosa. En la idea de illusio de Bourdieu, se ven claramente las influencias durkheimianas y wittgensteinianas que recibió. En Investigaciones filosóficas (Barcelona: Editorial Crítica, 1988 [1953], 547 p.), decía WitTGenstein: „El ideal, tal como lo pensamos, está inamoviblemente fijo. No puedes salir fuera de él: siempre tienes que volver. No hay ningún afuera; afuera falta el aire. - ¿De dónde proviene esto? La idea se asienta en cierto modo como unas gafas ante nuestras narices y lo que miramos lo vemos a través de ellas. Nunca se nos ocurre quitárnoslas" (p. 119). En Observaciones a La Rama Dorada de Frazer (Madrid: Editorial Tecnos, 1992 [1967], 91 p.), argumentaba, en contra de la tendencia de los antropólogos a no reconocer más pensamiento que el suyo: ‘He de sumergirme siempre, una y otra vez, en el agua de la duda. La idea (Darstellung) que Frazer se hace de las visiones (Anscbauungen) mágicas y religiosas de los hombres no es satisfactoria: presenta tales visiones como si fueran errores... Ya la idea de explicar una costumbre... me parece fuera de lugar. Todo lo que hace Frazer es reducirla a algo plausible a hombres que piensan como él. Es del todo extraño que todas estas costumbres se expongan, por decirlo de alguna manera, como tonterías. Y es que nunca es plausible que los hombres hagan todo esto por pura imbecilidad. (pp. 49-51).

4 Esta adhesión al orden establecido, tal como las investigaciones empíricas establecen en La distinción, op. cit., parece ser más completa tanto en las posiciones más desfavorecidas en el espacio social como en las posiciones más favorecidas del mismo. Esto se entenderá mejor si vemos que, en cambio, son las clases medias las que menos se acomodan a esta definición precisamente por la posición estructuralmente equívoca e inestable que ocupan: condenados a ser siempre más o menos de lo que realmente son, a adelantar su parecer por delante de su ser para intentar obtener los beneficios de esa estrategia de representación, parecen no estar nunca enteramente de acuerdo con la definición de su condición. 
política se empeñan en atribuir a ciertas clases sociales la responsabilidad de trabajar contra sí mismas cuando no siguen el comportamiento que ellos consideran políticamente racional (por ejemplo, con un voto en las urnas aparentemente a contrario de lo que se supone que deberían ser sus intereses; cuando, en situaciones de compentecia económica exterior, el afán cooperativista no existe prácticamente entre los obreros, etc.), sino que también los científicos sociales no son capaces de entender esta situación más que en términos de cooperación con el poder dominante o de simple y llana sumisión. La situación, sin embargo, tal como nos enseña Bourdieu, es radicalmente diferente: el modo de conocimiento dóxico quiere que las expectativas subjetivas alcancen hasta donde las condiciones objetivas dejen llegar, de manera que esa complicidad, que no se daría si no se diera al mismo tiempo el desconocimiento de la arbitrariedad de los límites establecidos por esas mismas condiciones, se resuelve, en todos los campos, incluido el político, mediante un comportamiento que expresa la conformidad y la congruencia con los límites propios de la condición. No es extraño, por eso, que la percepción política de la realidad varíe de acuerdo con las condiciones variables de producción de esa percepción y que esa percepción realizada influya a su vez en la generación o reproducción de las condiciones propias de esa percepción: esa fracción de la clase media en declive que, viendo traicionadas todas sus expectativas de promoción después de haber sacrificado el presente al futuro mediante contínuas y calculadas renuncias, no dudará, seguramente, en retraerse hacia posiciones más conservadoras, más acordes con la realidad de sus mermadas expectativas; o, también, esa fracción de la clase dominada que, pobre en capital económico y cultural experimenta un ligero ascenso y, en consecuencia, comienza a sentir la necesidad de reservar y acumular parte de su patrimonio presente para asegurarse un futuro acorde a la posición que desean ocupar, tomará, con mucha probabilidad, una actitud igualmente conservadora, poco consonante con lo que el líder político podría esperar de ella.

El habitus, según todo lo anterior, funciona de una manera elementalmente dóxica, es decir, hace de la necesidad virtud, de los límites insoslayables de la condición que como estructuras estructuradas quedan incorporadas en forma de principios de percepción y de todo un conjunto de disposiciones parejas en todo agente que pertenezca a esa condición, elecciones activas y conscientes en forma de estructuras estructurantes que discriman entre un estado determinado de la oferta de cualquier producto para seleccionar aquello que consideran adecuado a su condición o a la que desean alcanzar. Este complejo proceso, si hacemos caso a las voces de la calle, es vivido como un sentido innato de la capacidad de distinguir, es decir, como una capacidad intransitiva e increada de distinción, lo que en otros términos suele denominarse gusto. Intentar discutir sobre gustos es, como la observación popular 
advierte, condenarse a no encontrar resolución alguna, porque nada hay escrito ni nada podrá haber a no ser que se traicione el más inefable y mágico de los principios del conocimiento práctico o a no ser que alguien posea la dudosa capacidad de objetivar completamente las condiciones de producción de su propio juicio: la experiencia cotidiana y el funcionamiento natural del mercado refuerzan las certezas de los agentes, porque si el gusto es esa forma del juicio que lleva al estado incorporado los límites de la condición, las mercancias son esa tendencia de un sistema particular de producción a llevar al estado objetivado un conjunto jerarquizado de diferencias, y el encuentro entre uno y otras se vive, como dice Bourdieu, como el amor, como si existiera una predestinación indecible y estelar entre los miembros de una pareja de amantes ${ }^{46}$.

El gusto existe en tanto existe el gusto realizado, es decir, en tanto puede aprehenderse a sí mismo reconociéndose en los objetos que son los gustos objetivados, cuestión esta que nos lleva a afirmar que no existe el gusto mas que en el cambio, en la confrontación con los otros gustos, porque uno y otros buscan distinguirse constante y mutuamente, algo dentro de la lógica si pensamos que los gustos son sublimaciones de diferencias sociales previas y los objetos objetivaciones de esas diferencias. Las prodigiosas metamorfosis de los gustos y de las modas responden a una dinámica interminable de la que el concepto de campo y sus términos solidarios pueden dar buena cuenta: de una parte, en términos generales, cada uno de los grupos sociales quiere lo que, de todas maneras, está abocado a querer, porque lo deseado entra siempre dentro de los límites definidos por la condición a la que se pertenece. Esto, evidentemente, genera disputas inacabables en torno al tipo de consumo legítimo y al tipo legítimo de producto consumido, cuestiones ambas, como dijera Bourdieu, que se resuelven socialmente mediante la invocación a un sentido innato y singular de la distinción; de otra parte, debemos tener en cuenta que para que el consumo exista, debe existir, simultánea y semiautónomamente, un campo de producción de los bienes de consumo donde sus productores elaboren mercancias objetivamente jerarquizadas, buenas para satisfacer las apetencias de agentes previamente jerarquizados. Este campo de producción, relativamente autónomo respecto a la demanda externa directa, como cualquier otro, es un lugar de revoluciones y transformaciones controladas, porque aunque existan

\footnotetext{
". Pierre Botinmfi, "La métamorphose des goûts", Questions de Sociologie, op. cit., pp. 161-172; "Eléments d'une théorie sociologique de la perception artistique", Revue Internationale des Sciences Sociales, Les Arts dans la Société, XX, 4, (1968), pp. 640-664; "Sociologie de la perception esthétique", en Les sciences bumaines et l'oeurre d'art (Bruxelles: La Connaissance S.A., 1969, pp. 161-176, 251-254); „Des goûts artistiques et des classes sociales" (con Didier Eribon), Libération. 3-4 novembre (1979), pp. 12-13; "La perception du monde social: une question de mots?., Actes de la Recherche en Sciences Sociales. 52-53, juin (1984), pp. 13-14.
} 
contínuas modificaciones puntuales de la estructura del campo, mediante petición de regreso a las fuentes originales o mediante apelación a la necesidad de una renovación que tome como inspiración nuevas fuentes, nunca se pone en entredicho al campo en tanto que tal, es decir, en tanto que campo de luchas y de juego.

La colaboración objetiva entre los dos órdenes, uno incorporado y otro objetivado, no tiene conclusión, o, más bien, no tiene otra resolución, que la de proseguir alimentando la ilusión de que se llega a finales sucesivos donde las sucesivas modas cristalizan en modelos aparentemente definitivos, aunque eso no sea mas que la solidificación transitoria de un estado de relaciones de fuerza particular destinado a transformarse sucesivamente, bien por efecto de una demanda incrementada de un tipo particular de bienes que obedece a unas estrategias de distinción particulares, bien por causa de los enfrentamientos que se dan en el interior del campo de producción respectivo y que tienen como apuesta la transformación de la estructura del campo.

\section{CRf́tica sociológica de la educación}

Existen en la mayoría de las sociedades una clase de instituciones que tienen por cometido asignar a los agentes una identidad particular, esto es, un deber ser que se impone imperativamente no sólo a aquel que lo recibe como una nueva naturaleza a la que deberá acomodar todo proceder, sino a todos aquellos contemporáneos suyos que deberán reconocer en esa asignación estatutaria la constatación de la excelencia y diferencia de la naturaleza del individuo designado y distinguido. Bourdieu propone denominar a estos actos, ritos de institución ${ }^{47}$, superando al más ambiguo ritos de paso: entre el último aprobado y el primer suspenso en la lista de calificaciones de una escuela existe el mismo límite mágico que entre aquellos jóvenes que son iniciados en un misterio o en una nueva condición y aquellos otros que no lo serán nunca (mujeres, hombres cuya adscripción por nacimiento les coloque en una categoría indigna de recibir tal iniciación, etc.). A unos y a otros se les exige que acaten la

47 Pierre Bournter, "Les rites d'institution, Actes de la Recherche en Sciences Sociales, 43. juin (1982), pp. 58-63; "Les rites comme actes d'institution", en Les rites de passage aujourd'bui, P. Centlivres y J. Hainard (eds.), Actes du Colloque de Neuchâtel (Lausane: Fditions L'Age d'Homme, 1986, pp. 206-215); "Rites as acts of institution", en Honor and grace in anthropology, J.G. Peristiany y J. Pitt-Rivers (eds.), (Cambridge: Cambridge University Press, 1992, pp. 79-89); Ce que parler veut dire. L'économie des échanges linguistiques (Paris: Fayard, 1982; ed. esp. ¿Qué significa bablar? Economia de los intercambios lingüisticos, Madrid, Ediciones Akal, 1985, 160 p. Capítulo II, 2: -Los ritos de institución-, pp. 78-86); savoir ce que parler veut dire", Intervención en el Congrès de l'AFEF (Limoges: 30 octobre 1977), Le français aujourd'bui, 41, mars (1978), pp. 4-20. 
evidencia del límite establecido, lo que es lo mismo que decir, la certidumbre de que cierta clase de instituciones es capaz de hallar diferencias "naturalmente" inscritas en los agentes que se presentan a evaluación, lo que supone, en última instancia, asumir como diferencias de naturaleza natural lo que, deberíamos ya sospechar, es explotación de diferencias de hecho previas de naturaleza social. El rito de institución no actúa sobre el vacío, sino que suele trabajar, para mayor éxito de su estrategia, sobre divisiones cum fundamento in re, haciendo pasar, eso sí, lo que es una desigualdad de hecho por una discrepancia de derecho: la institución se encarga de inscribir casi indeleblemente en los hábitos mentales, verbales y corporales de los agentes la diferencia que les es propia y constitutiva, e insta categóricamente a los desplazados a que asuman como una incapacidad personal lo que no es sino efecto de una asignación social.

La institución escolar es la encargada en la actualidad de administrar e implementar legitimamente la ideología del don, esa vivencia popular que cree que la competencia cognitiva está irregularmente distribuida según los designios indescifrables de la naturaleza: mientras que la modalidad espontánea del conocimiento sea la del conocimiento dóxico, es decir, mientras el conocer no pueda ser otra cosa que la interiorización de los límites establecidos por las estructuras sociales, la institución académica, al sancionar legalmente como si se trataran de diferencias naturales lo que no son sino diferencias sociales, no hace otra cosa que reforzar la solidaridad originaria entre estructuras cognitivas y sociales, es decir, no hará otra cosa que reproducir las condiciones necesarias para reproducir las diferencias de clase que están en la base de la producción de las distintas aptitudes cognitivas ${ }^{48}$. El orden académico asegura, de esta

is Pierre Bolrntel, Les héritiers, les étudiants et la culture (Paris: Les Editions de Minuit, 1964, junto con J. C. Passfron; nueva edición aumentada, 1966; ed.esp. Los estudiantes y la cultura, Barcelona, Editorial Labor S.A., 1967); "Les étudiants et leurs études", Cabiers du Centre de Sociologie Européene, 1 (1964); "Langage et rapport au langage dans la situation pedagogique», en Rapport pédagogique et communication, P. Bourdieu, J. C. Passeron, M. de Saint-Martin (eds.) (Paris-La Haye: Ed. Mouton, Cahiers du Centre de Sociologie Européenne, 2, 1965. pp. 9-36); "L'école conservatrice, les inégalites devan l'école et devant la culture", Retue Française de Sociologie, VII, 3 juillet-septembre (1966), pp. 325-347; "Systèmes d'enseignement et sustèmes de pensée», Communication au VIe Congrès Mondial de la Sociologie (Evian, septembre, 1966), Revue Internationale des Sciences Sociales, Fonctions sociales de l'éducation, XIX, 3, (1967), pp. 367-388; wLe système des fonctions du système d'enseignement, en Education in France, M. A. Mattijssen y C. E. Vervoort (eds.), (La Haye: Mouton, 1969), pp. 181-189; La reproduction. Elèments pour une théorie du système d'enseignement (Paris: Les Editions de Minuit, 1970, con J. C. PAsseron: ed. esp. La reproducción. Elementos para una teoría del sistema de enseñanza, Barcelona, Editorial Laia, 1977); "L'excellence scolaire et les valeurs du système d'enseignement français", Annales, XXV, 1 , janvier-février (1970), pp. 147-175; Composition sociale de la population étudiante et chances d'accès à l'enseignement supérieur., Orientations, 41, janvier (1972), pp. 89-102; ales 
manera, el orden social, porque mientras la escuela reafirme, mediante un trabajo pedagógico dirigido a consolidar los hábitos cognitivos y de trabajo de una clase, las competencias que ya se poseían antes de entrar en ella, la discriminación social no parecerá deber nada a intereses sociales y sí a discapacidades naturales. Las polémicas que se reavivan periódicamente en torno al origen biológico o social de las diferencias del coeficiente de inteligencia, y que parecen haber atrapado a esa clase de psicología que se conforma con aplicar rudimentaria y mecánicamente tests elaborados para medir la discrepancia de las aptitudes y que no hace otra cosa que constatar la discrepancia de las condiciones sociales de producción de esas aptitudes y contribuir, de esa manera, a legitimar las diferencias sociales en nombre de la ciencia, no nos deberian hacer perder de vista que el problema no es tanto establecer si el origen de las diferencias es biológico o social -aunque biológicamente sea indemostrable la existencia de diferencias-, sino establecer cuales son los intereses asociados a las posiciones sociales que defienden una u otra opción. Defender empecinadamente el origen biológico de las discrepancias debería ponernos sobre la pista del interés de una posición social determinada por seguir haciendo pasar lo que son profundas desigualdades sociales por diferencias aleatorias de ciertas competencias cognitivas.

Las investigaciones estadísticas demuestran que el fracaso escolar incide sobremanera en aquellos grupos sociales cuyas condiciones de producción del entendimiento están particularmente mermadas: de una manera natural, los niños de los grupos sociales más desfavorecidos interiorizan muy tempranamente los límites de sus expectativas, que son, como sabemos bien, los límites de su condición social, de manera que rechazan activamente integrarse en un proyecto que no es el suyo, autoexcluyéndose y autoeliminándose, de paso, de la carrera por obtener un puesto o un empleo mejor que requieren la titulación que no han obtenido. El complemento lógico de esta actitud es la actitud que mantienen los padres respecto al futuro escolar de sus hijos: de nuevo, las estadísticas vienen a mostrar cómo la expectativa de escolarización que los padres expresan respecto al porvenir de sus hijos, no sobrepasa mas que muy excepcionalmente el grado alcanzado por los propios padres. De esta manera puede observarse cómo a través de tres generaciones y

stratégies de reconversion. Les classes sociales et le système d'enseignement, Information sur les Sciences Sociales, XII, 5, octobre (1973), pp. 61-113; sLe titre et le poste. Rapports entre le système de production et le système de reproduction, Actes de la Recherche en Sciences Sociales, 2, mars (1975), pp. 95-107 (ed. esp. "El título y el empleo-, Revista de Educación, 1980); "Epreuve scolaire et consécration sociale. Les classes préparatoires aux Grandes écoles", Actes de la Recherche en Sciences Sociales, 39, septembre (1981), pp. 3-70; -Variations et invariants. Eléments pour une histoire structurale du champ des grandes écoles", Actes de la Recherche en Sciences Sociales, 70, novembre (1987), pp. 3-30; Lan oblesse d'Etat. Grandes écoles et esprit de corps (Paris: Editions de Minuit, 1989, 568 p.). 
más se reproducen tanto los niveles escolares como las posiciones profesionales, cómo los hijos de obreros suelen conseguir trabajos de obreros y cómo los hijos de los grupos privilegiados suelen conseguir trabajos que, al menos, eviten los peligros del desclasamiento.

La ideología del don trabaja tanto más insidiosa y profundamente cuanto más es desconocida como tal, cuanto que cuenta con la complicidad de un instrumento que parece estar repartido de una manera tan universal e igualitaria, que difícilmente podría hacerse sospechoso de colaboración con una u otra clase: nos referimos al lenguaje y a la idea, aceptada globalmente al menos desde Saussure, del comunismo lingüistico, de la distribución y repartición uniforme e igualitaria de la competencia lingüística ${ }^{49}$. Sobre esta falacia, que no tiene en cuenta que no hay competencia sino competencias que dependen para su formación y desarrollo de condiciones sociales discrepantes, se asienta toda la pedagogía al uso: ni la capacidad de descifrar el mensaje hablado, ni la capacidad de desentrañar el lenguaje escrito, vienen dadas por igual, aunque la escuela se empeñe en ofrecer a todos sus alumnos el mismo producto que es objetivación de las condiciones en que fue creado y que coincide sólo con aquella parte del público cuyo entendimiento fue construido con el mismo conjunto de condiciones. Bourdieu nos recuerda ${ }^{50}$ que en las relaciones de comunicación que se establecen entre el profesor y el alumno, una modalidad posible de todas las relaciones de comunicación entre una parte dominante y otra dominada, no hace falta establecer explicitamente el modelo de comunicación para que se imponga taxativamente una definición de esa situación de comunicación, porque el lenguaje debe su poder no a algo que resida en él mismo sino, al contrario, a algo que reside fuera de él, a la posición social de quien lo utiliza: no nos preocupa tanto el hecho de que todos seamos capaces de hablar como el hecho de que no a todos se nos escuche por igual, porque la capacidad que tenemos de hacer cosas con palabras no depende de la fuerza de las palabras, sino de la fuerza de quien utiliza las palabras ${ }^{\text {1. }}$. De esa manera, como asegura Bourdieu, ala autoridad que funda la eficacia performativa del discurso es un percipi, un ser conocido

1" No sólo es responsable Saussure de esta idea que él contribuyó a fomentar con su comentario sobre el atesoro lingüistico" común de una comunidad hablante. También Chomsky ha contribuido de una manera fundamental a su propagación al plantear como problema cómo a partir de una evidencia fragmentaria del lenguaje, la que los padres pueden transmitir a sus hijos, se reconstruye el lenguaje tntero y se alcanza una competencia perfecta.

"Pierre Butrdif!, Ce que parler veut dire, op.cit; ¿Qué significa bablar? Economía de los intercambios lingüústicos, op.cit.

¿ En estos razonamientos es fácil ver la influencia de Nietzsche en Bourdieu: «El derecho del señor a dar nombres llega tan lejos que deberiamos permitimos el concebir también el origen del lenguaje como exteriorización del poder de los que dominan. (La genealogia de la moral, op. cit., p. 32). 
y reconocido, que permite imponer un percipere, o, mejor aún, que permite imponerse oficialmente como imponente, es decir, frente a todos y en nombre de todos, del consenso respecto al sentido del mundo social que funda el sentido común ${ }^{52}$. En estas circunstancias, la automarginación se convierte en la respuesta más económica de aquellos grupos objetivamente excluidos de la carrera escolar, porque si por su posición no tienen otra opción que acatar como portadora del sentido común aquella voz que debe su autoridad y su eficacia a la posición social que ocupa, no podrán vivir sus fracasos más que como fracasos personales, porque en ningún caso puede dudarse del sentido común y de sus "evidencias" elementales. Al contrario, aquellos grupos que comparten con los productos objetivados de la escuela las condiciones objetivas de posibilidad, las condiciones que han servido para producir el juicio y producir los productos escolares, no podrán vivir sus éxitos más que como logros exclusivamente personales, porque el lenguaje del sentido común dice que es el esfuerzo y la competencia personal los que alcanzan el éxito. Por si esta clase de violencia no bastara, las instituciones reparten reconocimientos oficiales entre todos aquellos que ya llevaban inscrito en su proyecto de realización personal - proyecto construido a partir de unas condiciones objetivas particulares que lleva a elegir ese conjunto de prácticas y objetos que más se adecúan a la condición y por tanto al proyecto- la potencialidad de acceder a la carrera académica y de obtener alguno de sus títulos: el efecto de asignación estatutaria del que habla Bourdieu, una de todas las posibles variantes de los ritos de institución, exhorta al individuo que recibe el título a que acomode completamente su ser al ser del título que recibe, a que transforme tanto como sea necesario sus hábitos perceptivos y activos hasta armonizarlos con los que exige la condición.

Una trayectoria familiar escogida, que pone en contacto a los agentes más jóvenes de la condición con los productos y las prácticas culturales más adecuadas a la condición; unas condiciones económicas lo suficientemente holgadas como para que, como decía Marx, puedan tener una vocación efectiva para el estudio ${ }^{53}$; un encuentro mágico, como el que describimos páginas atrás, entre dos historias que se entrecruzan, una en el estado incorporado -en forma de juicios y disposiciones-, otra en el estado objetivado -en forma de productos escolares $y$ formas de

52 Pierre Bor'rifn, ¿Qué significa hablar? Economía de los intercambios lingüisticos, op. cit., p. 66.

5. Karl MARx decía en Manuscritos: economía y filosofía (Madrid: Alianza Editorial, 1985, 251 p.): :Si tengo vocación para estudiar, pero no dinero para ello, no tengo ninguna vocación (esto es, ninguna vocación efectiva, verdadera) para estudiar. Por el contrario, si realmente no tengo vocación alguna para estudiar, pero tengo la voluntad y el dinero, tengo para ello una efectiva vocación. (p. 180). 
trabajo-; una carrera académica jalonada por sucesivas reafirmaciones institucionales, en forma de títulos, que vienen a avalar las certezas de "sentido común" que ya poseían previamente; y, en fin, un capital escolar y cultural acumulado, como consecuencia de todo lo anterior, que les hará entrar en superioridad de condiciones en todos los enfrentamientos por la obtención de puestos laborales y por el establecimiento del sentido legítimo del mundo social, son los elementos que concurren en la educación, proceso, como decía Coulon, que es tratado como una "caja negra" en la que solemos interesarnos por la entrada y la salida de variables para olvidarnos por completo del proceso de reproducción en el interior de la "Caja" 54 .

La Crítica sociológica de la educación que plantea Bourdieu, que también podríamos llamar la Crítica de la construcción escolar del juicio, es el complemento y corolario lógico de los análisis previos sobre la formación del juicio y sobre las funciones políticas del juicio en su dimensión científica o cotidiana, funciones tanto más violentas y paralizadoras cuanto menos se ahonde en los procesos de su producción y de su uso estratégico.

\section{Critica sociológica de la cultura}

Una de las formas de sustancialismo popularmente más extendida es aquella que aprecia o busca el valor de los objetos precisamente allí donde no puede estar, en los objetos mismos. Y es que, si aceptáramos que el valor de las cosas reside con exclusividad en las cosas mismas, no nos quedaría otro remedio que, para ser consecuentes, admitir que del lado humano, del lado de aquellos que tienen que apreciar y seleccionar los objetos, no existe predeterminación alguna, y que esa capacidad de apreciación y selección está desigual y caprichosamente repartida entre los miembros de una comunidad determinada. No perdemos de vista que, efectivamente, la historia del campo de producción de los bienes culturales (del literario, el pictórico, el musical, etc., y de la relación que cada uno de ellos ha mantenido históricamente con los otros) instaura una jerarquía objetiva de sus propios productos, porque el más avanzado de

s. A. Conion, La etnometodología (Madrid: Cátedra, 1988, 141 p.), pp. 101-102: *Todo ocurre como si la educación, en cuanto proceso, hubiera sido tratada como una caja negra. que se prescinde de analizar deliberadamente para interesarse por la entrada y salida. Se meten, a la entrada del sistema, variables input (sexo, edad, nivel socioeconómico de los padres, pertenencia étnica), y se obtiene, a la salida, el fracaso escolar, abandonos... de modo que el "hijo tendrá el mismo oficio que el padre., y la desigualdad se produce de nuevo. Pero no vemos cómo se fabrica esta reproducción en el interior de la "caja", es decir, en la escuela. Aunque la educación sea una variable mayor en sus propias teorías, los sociólogos no han examinado directamente los procesos educacionales. 
ellos, para poder realizarse, ha tenido que conocer y contener toda la historia de los productos anteriormente realizados. Sin embargo, el conocimiento de esta escala no le es dado mas que a unos pocos, a aquéllos que participan directamente en el campo como productores (escritores, artistas, músicos, etc.), o a aquellos que intervienen como generadores y difusores del interés por el campo (periodistas, comentaristas artísticos, conservadores de museos, etc.). Para el resto de los miembros de una comunidad, cuyo juicio no ha crecido en las condiciones que debería haberlo hecho para alcanzar la pureza y desinterés que Kant le exigía al juicio que percibe el arte, el campo de la cultura organiza y desorganiza de una manera completamente arcana, mediante las sucesivas transformaciones y golpes de efecto y de fuerza que la prensa se encarga de propagar, su propio orden. Una bistoria interna del arte se conformaría con creer en el lenguaje del arte y de los creadores de arte, que no tienen ningún interés en saber donde están y de donde proceden y que por eso se conforman con fomentar la ilusión del creador increado, con promover su propia hagiografía y elevarse a los cielos en compañía del demiurgo platónico ${ }^{55}$. De más está decir que las relaciones entre una verdadera sociología de la producción de las formas del conocimiento, que no respeta la ficción del autor aislado y encerrado en sí mismo -aunque no descarte la posibilidad de la existencia de autores que por sí mismos hayan constituido alguna vez una clase ${ }^{56}$ - y aquellas disciplinas en que está comprometida la "creación" artística, que no pueden comprender mas que como una forma de reduccionismo terrorista todo razonamiento que atente contra la complaciente idea que mantienen de sí mismas y de su alto cometido, no son exactamente de cooperación y mutuo entendimiento. La contestación que dio Picasso a la pregunta, ¿cómo puede entenderse el arte?, resume todos los temores de los creadores y de los que

55 Pierre Boltrden, "Mais qui a créé les createurs:., Questions de sociologie, op.cit., pp. 207-221; -Disposition esthétique et compétence artistique-, Les Temps Modernes, 295, février, (1971), pp. 1345-1378; "L'invention de la vie d'artiste*, Actes de la Recherche en Sciences Sociales, 2, mars, (1975), pp. 67-94; "The field of cultural production or the economic world reversed., Poetics, vol. 12, núm. 4-5, novembre (1983), pp. 311-356; "Le champ littéraire. Préalables critiques et principes de méthode», Lendemains, IX, 36, (1984), pp. 5-20; -Dialogue à propos de l'histoire culturelle (con R. Chartier y R. Darnton), Actes de la Recherche en Sciences Sociales, 59, septembre, (1985), pp. 86-93; L'illusion biographiquen, Actes de la Recherche en Sciences Sociales, 62-63, juin (1986), pp. 69-72 (ed. esp. "La ilusión biográfica", Historia y Fuente Oral, 2, (1989), pp. 27-33); "The historical genesis of pure aesthetic", The Journal of Aestbetics and Art Criticism, vol. XIVI, Special Issue, (1987), pp. 201-210; "La revolution impressionniste*, Noroit, 303, septembre-octobre (1987), pp. 3-18; "Flaubert's point of view:, Critical Inquiry, 14, Spring, (1988), pp. 539-562.

56 Autores como Sartre, Flaubert o Manet, constituyen. en sus respectivos campos, auténticas clases particulares, tal como destaca Botriplfi en "Sartre., London Review of Books, vol. 2, 22, 20 November-3 December (1980), pp. 11-12; *Flaubert's point of viewn, op. cit.; -La revolution impressionniste, $o p$. cit. 
participan en el campo de divulgación del valor del arte a propósito de la más mínima posibilidad de comprender, explicar o dar cuenta de ese fenómeno: "Todo el mundo quiere entender el arte... ¿por qué no intentar entender el canto de un pájaro?... La gente que trata de explicar un cuadro está por lo general tomando el rábano por las hojas " ${ }^{57}$. La fenomenología de la experiencia artística no basta en absoluto para explicar el proceso de creación, proceso que sólo puede entenderse en términos de la relación del artista considerado con el resto de los artistas, es decir, en términos del funcionamiento del campo de producción artístico, y en términos del conjunto de agentes relacionados con la producción del reconocimiento del valor social de la obra (críticos, mecenas, conservadores, directores de galerías, etc.). Sólo mediante el análisis de la relación entre el habitus socialmente constituido del autor y la posición que ocupa en la división del trabajo de producción cultural, podremos tener la posibilidad de comenzar a atisbar qué significa eso de la creación. Si los que están insertos en el campo de producción cultural no son desde luego los mejor situados para plantear una sociología de sus propios proyectos y opiniones, no lo son tampoco todos esos profesores-autores mediáticos que, a la manera de Eco o Steiner, quieren obtener el doble beneficio que supone estar fuera del campo - por su condición profesoral- y participar de las creencias inherentes al campo -por su condición de artistas-.

Si todo esto tiene alguna importancia, excepción hecha del conocimiento del funcionamiento y dinámica de un campo particular, es porque en la realidad cotidiana se presentan multitud de interacciones en las que lo que se dirime es la excelencia o brutalidad del juicio que es o no capaz de apreciar los bienes culturales legítimos y, con ello, la posición social que, en consecuencia, se merece. El problema llega cuando todos esos intelectuales, artistas y escuelas que no tienen otra razón de ser que la de hacerse reconocer a través de sus actitudes y sus palabras como poseedores de una posición preminente en el campo de producción cultural -posiciones y opiniones que se ocupan y se expresan por relación al resto de las posiciones y opiniones y por relación al resto de tomas de posición y tomas de opinión-, pretenden imponer a la población ajena a esas luchas la definición de lo que es o no legítimo consumir, ver, leer o escuchar. No son menos cómplices de esta situación todos esos intelectuales aparentemente bienintencionados que, en nombre del comunismo cultural que debe salvaguardarse, opinan que la "cultura" debe ser un bien universalmente accesible, aunque, eso sí, no hasta el punto en que la masificación vulgarize lo que tanto tiempo ha costado refinar, $y$ no hasta el punto en que se preocuparan menos de proferir

\footnotetext{
5" Recogida en Clifford GFrRT,, "Art as a cultural system", Local knowledge. Further essays in interpretite anthropology, (New York: Basic Books. Inc. Publishers, 1983, 244 p.), p. 94.
} 
palabras fáciles y más de procurar las condiciones objetivas necesarias para facilitar un desarrollo paralelo del conocimiento de los candidatos. Los trabajos de Bourdieu a propósito del efecto de imposición y discriminación diferencial que los bienes culturales legítimos ejercen sobre las diferentes clases sociales, y el uso que de él se hace en las luchas por la ocupación de una posición determinada en el espacio social ${ }^{58}$, son muy claros: las clases dominantes, en capital económico o cultural, detentan el monopolio del dictamen del gusto. Su desenvoltura en el trato con las obras de arte, efecto sin duda de la trayectoria familar previa, de la educación y de las condiciones objetivas en que creció su juicio, les lleva a arriesgarse en aquellos terrenos donde un juicio inexperto no osaría hollar. Sus elecciones en lo que respecta a obras culturales manifestan el gusto por lo más difícil e inaccesible; las clases que ocupan una posición media se encuentran condenadas a la hipercorreción, a la aceptación completa de lo que ha sido definido como legítimo, por tanto indiscutible, cosa que les lleva a exhibir lo que Bourdieu ha denominado buena voluntad cultural, no lo suficientemente buena, sin embargo, para acceder a las posiciones que corresponderían, porque un exceso de corrección es siempre síntoma de una carencia que se suple con un exceso de vocación. En todo caso, debido a la imperfección de su formación y a la dudosa calidad de su capital cultura, eligen prácticas culturales incompletas y sospechosas: la fotografía, el cine y la cinefilia, el comic, prácticas todas tan desclasadas como desclasantes; las clases más desfavorecidas, por último, siguen siendo presa, como decía Marx, de sus necesidades y de sus preocupaciones ${ }^{59}$, y su gusto está hecho a la medida de sus posibilidades objetivas: su nivel de lectura es, efectivamente, esta-

‘n Pierre Bolirint; "Les musées et leurs publics", L'expansion de la Recherche Scientifique, 21, décembre (1964), pp. 26-28; "Le musée et son public", L'Information d'Histoire de l'Art, 3, mai-juin, (1965), pp. 120-122; Un art moyen, essai sur les usages sociaux de la photographie (Paris: Editions de Minuit, 1965); L'amour de l'art, les musées d'art et leur public (Paris: Editions de Minuit, 1966; ed. aumentada L'amour de l'art, les musées d'ant européenes et leur public, Paris: Editions de Miniut, 1969, 251 p.); "La transmission de l'héritage culturel", en Les partages des bénéfices, expansion et inégalités en France (Paris: Editions de Minuit, 1966, pp. 383-420); ¿Disposition esthétique et compétence artistique., Les Temps Modernes, 295, février (1971), pp. 1345-1378; *Reproduction culturelle et reproduction sociale». Information sur les Sciences Sociales, X, 2, avril, (1971), pp. 45-99: "La critique du discours lettré", Actes de la Recherche en Sciences Sociales, 5-6, novembre (1975), pp. 4-8; .Des goûts artistiques et des classes sociales(con Didier Eribon), Libération, 3-4 novembre (1979), pp. 12-13; Consommation culturelle-, en Encyclopaedia Universalis, t. 2, (1984), pp. 779-782; "Pour une critique de la lecture" (Strasbourg: Centre de Documentation en Histoire de la Philosophie, 1984), "La lecture II", Cabiers du Séminaire de Pbilosophie, 2 (1984), pp. 13-17; .La lecture: une pratique culturelle", en Pratiques de la lecture (Paris: Rivages, 1985, pp. 218-239); "Lectura, lectores, letrados, literatura", en Cosas dichas, op.cit., pp. 115-124.

59 Karl Marx, Manuscritos: economía y filosofía, op. cit, p.150: .El hombre necesitado, cargado de preocupaciones, no tiene sentido para el más bello espectáculo*. 
dísticamente irrelevante; sus elecciones musicales se decantan por los aires fáciles y populares; su interés por la pintura podrá manifestarse, en todo caso, como estupefacción o incomprensión.

De la misma manera que la alta peluquería no existe sin la peluquería, la alta cocina sin la cocina, la alta costura sin la costura y así sucesivamente, porque cada uno de los términos no existe si no es por su relación con el otro, por las luchas por el establecimiento de la definición y la práctica legítima que generan por sí mismas el interés por el objeto por el que se disputa, así la alta cultura no existe sin la cultura y sin la falta de cultura, porque lo auténtico, sublime y extraordinario no existe sin lo falso, despreciable o común, y ni siquiera existiría el interés por la cultura y el interés de la cultura si no existiera un enfrentamiento entre los términos antagónicos. Y es que, efectivamente, los hechos culturales, la cultura, tiene valor porque quienes con sus actos demuestran que están interesados en monopolizar y en imponer un estilo de vida y unas prácticas culturales legítimas, generan una forma de dialéctica de la distinción donde las cosas se definen siempre negativamente unas con respecto a las otras. Calificadas siempre con uno de los adjetivos que forman los pares de oposición (distinguido/vulgar; delicado/chabacano; fino/grueso; bonito/feo...), las prácticas culturales encuentran su fuerza motriz tanto en que la dinámica de la apropiación simbólica es un proceso interminable, porque se redefine constantemente contra lo que es diferente, como, sobre todo, en que la creencia en el valor de la cultura de todos los que participan en este enfrentamiento, soporta su misma existencia. El interés por la cultura, que siempre se disfraza de sublime desinterés porque la violencia racista y terrorista de la imposición del gusto no puede ejercerse más que a través de una forma desfigurada, no puede esconder, tras el análisis de Bourdieu, que quienes definen el valor y el interés de la cultura no son sino aquellos que más interesados y afectados están por la cultura, quienes en el establecimiento de esa escala de la autenticidad y la ortodoxia generan una gradación paralela de los gustos y de los individuos que los manifiestan.

Fl trabajo de Bourdieu es, efectivamente, una Crítica sociológica de la cultura, o, como también podría denominárselo, para ligarlo con el resto de sus investigaciones y establecer claramente los nexos de unión, una Crítica del uso cultural del juicio, porque sólo poniendo al descubierto las luchas y estrategias simbólicas que tienen por apuesta el campo de la cultura y sus productos, podremos tener la posibilidad de comenzar a evitar el exclusivismo intransigente de los privilegiados y empezar a ofrecer las condiciones realmente necesarias para la que la cultura sea un bien universalmente accesible. 


\section{LA UNIVERSAL INTELECTUAL}

Detrás de la inmensa y sólida obra de Bourdieu late un propósito, que el pudor no siempre le ha dejado expresar explícitamente, moral, aunque más bien deberíamos decir liberador, pero liberador en un sentido amplio, no solamente centrado en esas situaciones donde evidentemente la dominación se impone a través de las estrategias eufemizadas de la violencia simbólica, sino en toda situación donde cualquier hombre permanezca preso, ignorándolo, de las brutales exigencias de su propia condición, coacciones que, naturalizadas a través del habitus, se imponen con la evidencia de lo natural.

La responsabilidad de desarrollar este proyecto no puede recaer en las espaldas de un sólo autor, por mucha que sea su impensable capacidad de trabajo y por muy afinado que sea su armamento conceptual. porque sólo convirtiéndose en un compromiso global de los intelectuales podrá hacerse realidad, no sólo porque una fuerza crecida suponga una fuerza creciente, sino porque habremos trasladado a cada uno de los intelectuales la responsabilidad de luchar contra esos otros intelectuales que no dudan en recurrir a cualquier arma política o económica para triunfar a cualquier precio en las luchas intelectuales. Darse las condiciones de posibilidad de la creación de una universal intelectual que reclame para sí la fuerza que le es propia, como ha hecho Bourdieu al multiplicar los controles sobre el propio campo intelectual y sobre el resto de los campos, es poner las bases de ese proyecto liberador ${ }^{60}$.

No hay seguramente mejor manera de terminar que recogiendo aquella presentación anónima -impersonal por tratarse de un proyecto colectivo pero redactada por la mano de Pierre Bourdieu- de uno de los planes más globales y globalizadores pensados por el científico social más deslumbrante de nuestra época, el de Liber.

Tan sólo un esfuerzo sostenido para superar los provincianismos y los particularismos, tanto de las disciplinas y de las especializaciones como de las tradiciones y de las capillitas que se gratifican con la admiración mutua, puede contribuir a crear las

6) Pierre Bollrdify, "Retrouver la tradition libertaire de la gauche- (con R. Pierre y D. Eribon), Libération, 23 décembre (1981), pp. 8-9; "D’abord défendre les intellectuels" (con D. Eribon), Le Nouvel Observateur, 12-18 septembre (1986), p. 82; "The corporatism of the Universal., Telos, 81, fall (1989); „Presentación., Liber, $\mathrm{n}^{2}$ 1, miércoles 11 de octubre (1989), p.2; -Les conditions sociales de la circulation internationale des idées* (Freiburg, 30 oct. 1989), Romanistische Zeitschrift für Literaturgeschichte; Cabiers d'bistoire des littératures romanes, $14 \mathrm{e}$ année, 1-2 (1990), pp. 1-10; "Epilogue: on the possibility of a field of world sociology", en Social Theory for a Changing Society, Pierre Botirdit: y S. Colfman (eds.), (Boulder-San Francisco-Oxford: Westriew Press, New-York: Russel Sage Foundation, 1991), pp. 373-387; .Bourdieu's road to a universal state, Guardian Weekly, February, 2, (1992), p. 16; -Le responsabilité des intellectuels, Liber, núm. 14, juin (1993), p. 2. 
condiciones para una libre circulación de las ideas, y así hacer posible un auténtico universalismo intelectual ${ }^{61}$.

\section{JOAQUíN RODRÍGUEZ LÓPEZ}

El artículo trata de resumir el contenido de los trabajos de Pierre Bourdieu y de encontrar el hilo argumental que une áreas de trabajo aparentemente inconexas: a través de las categorías de campo, habitus y doxa, desarrolladas por el autor, se llega al problema de la construcción social del entendimiento y de ahí al uso cotidiano y contextual que de él se hace y a través del que se construye el sentido social de la realidad.

The paper deal with the summing up of the content of Pierre Bourdieu's works and the searching of the line of argument that links seemingly unrelated fields of work: trough the categorys of field, habitus and doxa, developed by the author himself, we reach to the problem of the social construction of understanding and judgement and, through that, to its daily and contextual use and to the social construction of the sense of reality.

(3) Liber, núm. 1, miércoles 11 de octubre de 1989, p. 2. Liber es un suplemento europeo de libros cuyos seis primeros números fueron publicados conjuntamente por El País, Le Monde. Frankfurter Allgemeine Zeitung, L'Indice y The Times Literary Supplement. Hoy, por razones que nos son desconocidas, y a partir del séptimo número. se publica como suplemento de la revista Actes de la Rechercbe en Sciences Sociales. 